\title{
Native Yeasts and Lactic Acid Bacteria Isolated from Spontaneous Fermentation of Seven Grape Cultivars from the Maule Region (Chile)
}

\author{
Wendy Franco ${ }^{1,2, *(\mathbb{D})}$, Sergio Benavides ${ }^{3}\left(\mathbb{D}\right.$, Pedro Valencia $^{4}\left(\mathbb{D}\right.$, Cristian Ramírez ${ }^{4}$ and Alejandra Urtubia $4(\mathbb{D}$ \\ 1 Departamento de Ingeniería Química y Bioprocesos, Pontificia Universidad Católica de Chile, \\ Ave. Vicuña Mackena 4860, Santiago 7820244, Chile \\ 2 Departamento de Ciencias de la Salud, Carrera de Nutrición y Dietética, Pontificia Universidad Católica de Chile, \\ Ave. Vicuña Mackena 4860, Santiago 7820244, Chile \\ 3 Núcleo de Investigación en Agroalimentos y Nutrición Aplicada, Universidad Adventista de Chile, \\ Camino a las Mariposas km 12, Chillán 3780000, Chile; sergiobenavides@unach.cl \\ 4 Departamento de Ingeniería Química y Ambiental, Universidad Técnica Federico Santa María, \\ Ave. España 1680, Valparaíso 2390123, Chile; pedro.valencia@usm.cl (P.V.); cristian.ramirez@usm.cl (C.R.); \\ alejandra.urtubia@usm.cl (A.U.) \\ * Correspondence: wfranco@ing.puc.cl; Tel.: +56-223545983
}

check for updates

Citation: Franco, W.; Benavides, S.; Valencia, P.; Ramírez, C.; Urtubia, A. Native Yeasts and Lactic Acid Bacteria Isolated from Spontaneous Fermentation of Seven Grape Cultivars from the Maule Region (Chile). Foods 2021, 10, 1737. https:// doi.org/10.3390/foods10081737

Academic Editors: M. Carmen Vidal-Carou and Maria Aponte

Received: 25 May 2021

Accepted: 15 July 2021

Published: 28 July 2021

Publisher's Note: MDPI stays neutral with regard to jurisdictional claims in published maps and institutional affiliations.

Copyright: (c) 2021 by the authors. Licensee MDPI, Basel, Switzerland. This article is an open access article distributed under the terms and conditions of the Creative Commons Attribution (CC BY) license (https:/ / creativecommons.org/licenses/by/ $4.0 /)$.

\begin{abstract}
Grapes are a source of native yeasts and lactic acid bacteria (LAB); however, the microbial make up is dependent on the grape cultivar and the regional growth conditions. Therefore, the aim of this study was to characterize the yeast and LAB in seven grape cultivars cultivated in Chile. Grape juices were fermented at $25^{\circ} \mathrm{C}$ for 7 days. Samples were collected to analyze sugar, organic acids, and ethanol. Microbial evolution was measured with culture-dependent and molecular approaches. Then, a native isolated Candida oleophila was selected for further sequential fermentations with Saccharomyces cerevisiae. The grape cultivars in the Maule showed a diversity of non-Saccharomyces yeasts, with a greater diversity observed at the beginning of the fermentation. However, species from the Hansenasporia, Metschnikowia, Torulaspora, Lachancea, and Candida genera were detected after 7 days, suggesting tolerance to environments rich in ethanol, capability may be associated to the terroir studied, which is characterized by torrid weather and antique and traditional vineyards. The alcoholic fermentation negatively impacted the LAB population, and after 7 days only Leuconostoc mesenteroides was isolated. In the sequential fermentations, C. oleophila was able to produce fermented grape juices with $<1.5 \mathrm{~g} / \mathrm{L}$ glucose, $12.5 \%(v / v)$ alcohol, and low concentrations of malic $(<1.00 \mathrm{~g} / \mathrm{L})$ and succinic $(2.05 \mathrm{~g} / \mathrm{L})$ acids, while acetic acid reached values $>0.3(\mathrm{~g} / \mathrm{L})$. To our knowledge this is the first time $C$. oleophila has been reported as a potential starter culture for wine production. However, more studies are necessary to fully characterize the potential of C. oleophila on wine attributes.
\end{abstract}

Keywords: native yeasts; Chile; wine; non-Saccharomyces; lactic acid bacteria; Candida oleophila

\section{Introduction}

Wine fermentation is a process that develops from a complex mixture of native microorganisms, which act sequentially and proliferate or decline as fermentation progresses. The establishment of yeasts and LAB during the fermentation process determines the wine quality and specific attributes [1]. In order to better control the fermentation, commercial strains (usually Saccharomyces spp.) are used. However, in recent years, several non-traditional strains have been studied and applied for winemaking, with the aim to enrich wine aromatic and flavors profiles [2,3].

Non-Saccharomyces yeasts are often autochthonous and can be found and isolated from grapes, spontaneous fermentations, and winery equipment [4-6]. Among these, the greatest diversity of yeasts can be found on grapes and fresh grape juice. Diversity is associated with climate conditions (rainfall, temperature) [7], terroir [8,9], maturity of 
the grapes [10], damage caused by insects or birds [11], and chemical agents that can be used during the grapes' cultivar [11,12]. Distinct yeast profiles might be related to the unique conditions according to the geographical and agricultural crop procedures used in each vineyard.

Although these native yeasts are less competitive than S. cerevisiae, they play a significant role during the early fermentation stages. They can influence the characteristics of the resulting wine by producing extracellular enzymes and metabolites of oenological significance, and therefore modify sensory and organoleptic properties [4,13-18]. The wine industry is actively seeking for diversification of its wine offer, targeting premium wines with specific flavor profiles. In that sense the use of non-Saccharomyces yeasts is of interest [19]. These yeast are able to convert non-volatile compounds into volatile aroma, therefore influencing the varietal flavors [20-22].

Even though selection and isolation of non-Saccharomyces yeasts is commonly done from grapes and fresh grape juice, in recent years, the characterization of spontaneous fermentations has led to the isolation a greater number of non-Saccharomyces yeast species [10,14,23-28]. The isolation of yeasts from spontaneous fermentations permits the identification of strains that show desirable attributes for winemaking during alcoholic fermentation $[13,22,29,30]$. However, in order to use non-Saccharomyces strains, some attributes need to be accomplished. The yeasts need to be competitive enough to grow along with S. cerevisiae and other microbiota present in the grape juices, to tolerate certain levels of alcohol to avoid stuck fermentations, and to grow at high sugar concentrations. They also resist sulfur dioxide that is commonly added to fresh grape juices as part of the standardization procedures, produce low quantities of hydrogen sulfide, and result in wines with low volatile acidity, among others [15].

About 40 non-Saccharomyces yeasts isolated from different sources have been studied [2]. The most common genera isolated and characterized are Hanseniaspora [16,31-34], Torulaspora [13,17,18,35,36], Metschinokowia [37-40], and Lachancea [13,41-43]. These yeasts have been used in single, co-culture, and sequential fermentations, and the findings led to a better understanding of their role in winemaking and the positive and/or negatives effect they might exert [2,44-47].

On the other hand, lactic acid bacteria (LAB) play an important role during and after the alcoholic fermentation, by producing lactic acid from the decarboxylation of the malic acid left in the fermented grape juice and thus increasing the wine $\mathrm{pH}$. Although species of Oenococcus are the most fitted to conduct the malolactic fermentation (MLF), other LAB genera are also involved in the process (Lactobacillus, Leuconostoc, Pediococcus, and Weissella). During alcoholic fermentation, the LAB evolution is influenced by the yeast diversity, and bacterial-yeast interactions might affect the malolactic fermentation during this stage [48].

Ecological surveys have been carried out extensively with the aim of characterizing the microbiota from grapes, grape juices, and wines from different regions [10,11,25-28,48-50]. However, to our knowledge, little information is available for wines produced in South America, and in particular from Chile. Jara et al., (2016) studied the presence of five nonSaccharomyces genera (Metschnikowia, Hanseniaspora, Torulaspora, Debaryomyces, Meyerozyma, and Rhodotorula) in grape juice from different regions in Chile [51]. The authors found that all the genera were present, but with different abundances, probably associated with the climate conditions surrounding the vineyards. Although the importance of the study, no information associated to what happens to the yeasts diversity during the alcoholic fermentation has been reported. Similarly, for bacteria, few studies have reported if and how the alcoholic fermentation influence the bacterial diversity [51].

In Chile, wine is the second largest food export commodity, and the country's production is rich and varied. Wine elaboration is mostly carried out using commercial S. cerevisiae strains with few commercial non-Saccharomyces yeasts used. Given the microbial diversity and the potential of native non-Saccharomyces yeasts over wine attributes, the goals of this study were (1) to isolate native yeasts and LAB present in different Chilean grapes commonly used for wine production, focusing on the microbial composition at the be- 
ginning and during spontaneous alcoholic fermentation; (2) to characterize the alcoholic fermentative profile of selected yeast isolates in laboratory fermentations; and (3) to study (at a laboratory scale) the ability of selected isolates to ferment grape juice in sequential fermentations with S. cerevisiae. The long-term goal of these initial studies is to characterize native microorganisms with potential as cultures for the elaboration of wines with distinct attributes.

\section{Materials and Methods}

\subsection{Grape Berries Samples and Grape Juice Preparation}

Grape berries were collected from the Palo Alto Winery located in the Maule Region $\left(35^{\circ} 26^{\prime} \mathrm{S} 71^{\circ} 40^{\prime} \mathrm{W}\right.$, Chile, Figure 1) during the 2013 vintage season (March to May). Seven grape varieties were chosen (Cabernet Sauvignon, Carignan, Chardonnay, Merlot, Pinot, Syrah, and S. Blanc). Sampling for each variety was conducted as follows. Within a barrack, four equidistant streets were selected. On each street, 10 grape clusters were randomly hand-picked following a zig-zag pattern. Samples were collected in triplicate and transported refrigerated to the Food Microbiology Laboratory at Pontificia Universidad Católica de Chile (Santiago, Chile). Upon arrival, clusters' stems and leaves were separated manually from each grape. The berries were processed using a food blender MiniPymer (Oster, China) at minimal speed. Extra care was taken to not break seeds. The resulting pulp was then filtered with a gauze to separate seeds and large particulates. The grape juice's initial nitrogen content was adjusted to $250 \mathrm{mg} / \mathrm{L}$ of yeast amino nitrogen (YAN) with diammonium phosphate salts (Sigma Aldrich, Saint Louis, MO, USA) and the $\mathrm{pH}$ was adjusted to 3.5 .

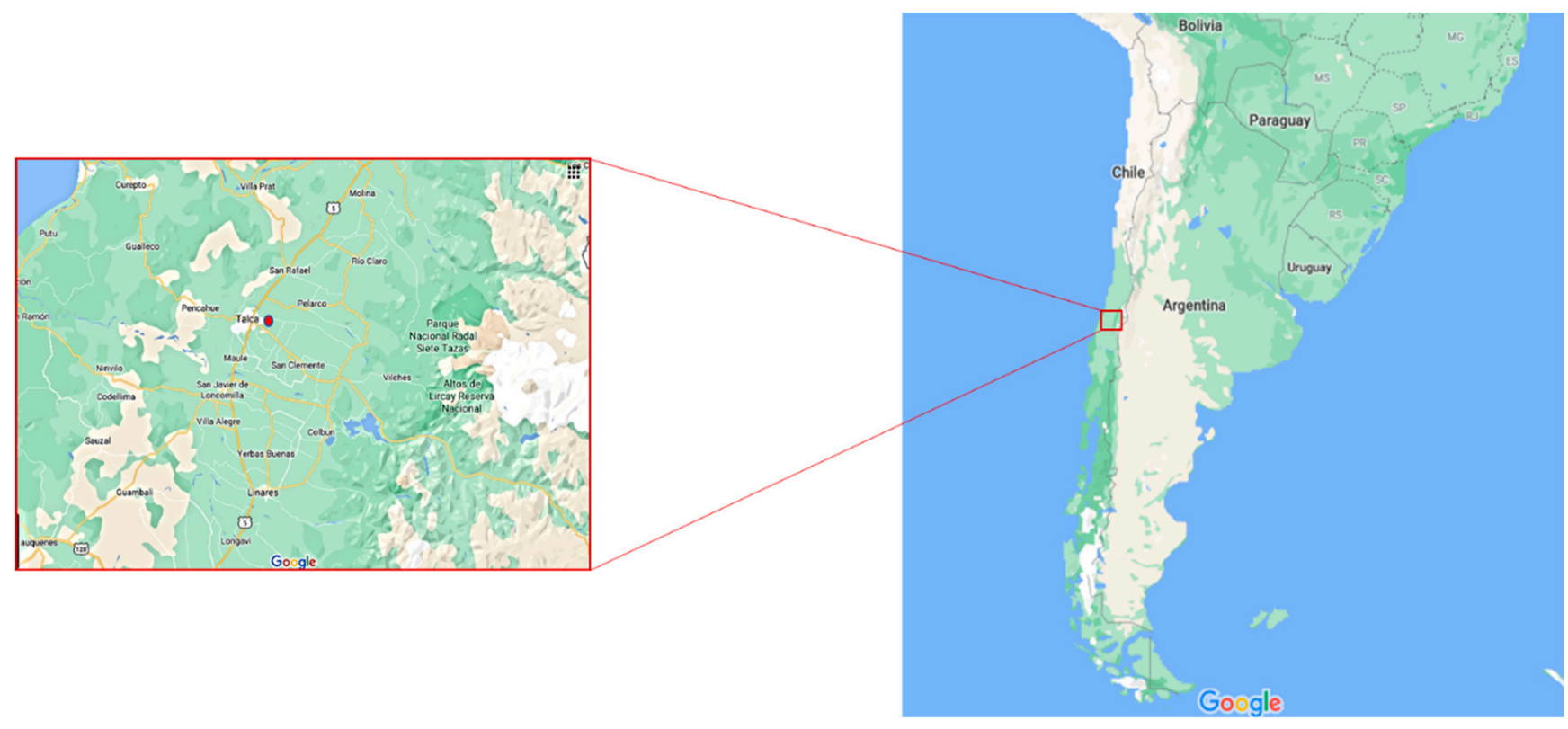

Figure 1. Location of the vineyard samples from which grapes were collected.

\subsection{Spontaneous Fermentation}

In triplicate, $400 \mathrm{~mL}$ of grape juice was placed in a sterile $500 \mathrm{~mL}$ Erlenmeyer flask provided with an airlock. Flasks were incubated in an orbital shaker incubator (Stuart, Staffordshire, UK) at $100 \mathrm{rpm}$ at $25^{\circ} \mathrm{C}$ for 7 days. Aliquot samples were collected daily.

\subsubsection{Chemical Analysis}

The $\mathrm{pH}$ of the samples was monitored using a $\mathrm{pH}$ meter (Accumet Fisher Scientific, Pittsburgh, PA, USA). Organic acids, sugar, ethanol, and glycerol concentrations were measured with high-performance liquid chromatography (HPLC) using an Amimex HPX/87H 
anion-exchange column (Bio/Rad Laboratories, Hercules, CA, USA). The column temperature was held at $55^{\circ} \mathrm{C}$, and sample components were eluted with $5 \mathrm{mM}$ sulfuric acid at a flow rate of $0.5 \mathrm{~mL} / \mathrm{min}$. A LaChrom L-7450A diode array detector (Hitachi, Tokyo, Japan) set at $210 \mathrm{~nm}$ was used to quantify organic acids. A LaChrom L-7490 refraction index detector (Hitachi) connected in series with the diode array detector was used to measure glucose, fructose, ethanol, and glycerol. External standardization of the detectors was done using six concentrations of the standard compounds [52].

\subsubsection{Culture-Dependent Analysis}

Microbiological Characterization

For the microbial characterization, the method reported by Franco et al., (2012) was followed. Briefly, collected samples were serially diluted in $0.01 \%$ peptone water (Sigma Aldrich) and spread platted. Yeasts were enumerated using yeast extract glucose chloramphenicol agar (YGC agar, Sigma Aldrich) and Wallerstein Laboratory nutrient agar (WLN agar, Oxoid, Hampshire, UK) supplemented with diphenyl (500 mg/mL) to prevent mold growth [53]. Plates were incubated aerobically at $25{ }^{\circ} \mathrm{C}$ for at least $48 \mathrm{~h}$ or until colonies were observed on plates. LAB were enumerated using de Man, Rogosa, and Sharpe agar (MRS agar, Oxoid) supplemented with $1 \%$ cycloheximide $(0.1 \%$ solution, Oxoid) to inhibit yeast growth. MRS agar plates were incubated anaerobically using gas packs (Oxoid) at $30{ }^{\circ} \mathrm{C}$ for $48 \mathrm{~h}$ or until colonies were observed [54].

Isolation and Identification of Microorganisms

The colonies visually observed in the agar plates were grouped according to their morphology. Four characteristic parameters were used for the classification: color, shape, elevation, and margin [42]. Four to five independent clones (colonies) of the representative morphology types were picked and streaked in the respective culture medium. Frozen stocks of all isolates were prepared in MRS and YGC broth for BAL and yeasts, respectively, containing 15\% glycerol (Sigma Aldrich).

Microbiological isolates (yeasts and bacteria) were identified through partial sequencing of the $26 \mathrm{~S}$ or $16 \mathrm{~S}$ rDNA, respectively. Chromosomal DNA was obtained using GeneJET Genomic DNA Extraction and Purification Kit (Thermo Scientific, \#K0722, Hampshire, UK). Both bacterial and yeast DNA were amplified by polymerase chain reaction (PCR) under the following conditions. For the bacterial isolates, the forward and revers primers (27F/1492r for the bacterial isolates $[55,56])$ were mixed with the chromosomal DNA. The PCR conditions were stage 1: $94{ }^{\circ} \mathrm{C}$ for $3 \mathrm{~min}$; stage 2: $94{ }^{\circ} \mathrm{C}$ for $1 \mathrm{~min}, 57^{\circ} \mathrm{C}$ for $2 \mathrm{~min}$, $72{ }^{\circ} \mathrm{C}$ for $2 \mathrm{~min}$, repeated 25 times; stage 3: $72{ }^{\circ} \mathrm{C}$ for $7 \mathrm{~min}$; and stage $4: 4{ }^{\circ} \mathrm{C}$ until use. For the yeast isolates, the forward and reverse primers NL-1/NL-4 were used [57] under the following PCR conditions: stage 1: $95^{\circ} \mathrm{C}$ for $5 \mathrm{~min}$; stage $2: 95{ }^{\circ} \mathrm{C}$ for $1 \mathrm{~min}, 52{ }^{\circ} \mathrm{C}$ for $45 \mathrm{~s}, 72{ }^{\circ} \mathrm{C}$ for $1 \mathrm{~min}$, and repeated 35 times; stage 3: $72{ }^{\circ} \mathrm{C}$ for $7 \mathrm{~min}$; and stage $4: 40{ }^{\circ} \mathrm{C}$ until use. All primers were obtained in Macrogen (Seoul, Korea). The PCR products were purified using the Qiagen PCR purification kit and sequenced by Macrogen (Seoul, Korea). The sequences obtained were subjected to the basic local alignment search tool (BLAST 2.2.26) [58] in the GenBank [59] non-redundant nucleotide database for yeast cultures and the 16S rRNA microbial database for bacterial cultures to determine identities. Only alignment matches with 95\% identity or higher, with no gaps, and expected values of 0.0 , were considered for identification purposes. The sequences are available at the National Center for Biotechnological Information (NCBI) GenBank' through their access numbers.

\subsubsection{Culture-Independent Analysis}

Preparation and Sequencing of the Grape Juices' Fermentation rDNA Libraries

Samples collected at the beginning of the fermentation (day 0), and after 7 days, were subjected to DNA extractions and sequencing data processing. The protocol reported by Franco et al., (2020) was followed for the preparation and sequencing of the grape juice's fermentation rDNA libraries [60]. Briefly, cells harvested from $10 \mathrm{~mL}$ of fermented grape juice 
were re-suspended in sterile saline and were treated to eliminate dead bacterial/yeast and extracellular DNA with $2.5 \mathrm{mM}$ propidium monoazide (PMA) stock solution $(1.3 \mathrm{mg} / \mathrm{mL}$ PMA in 20\% DMSO; Biotium, Inc., Hayword, CA, USA) following the method described by Pan and Breid (2001) [61]. PMA-treated samples were stored as cell pellets at $-20{ }^{\circ} \mathrm{C}$ until DNA extraction was performed. Total genomic DNA was extracted using a MasterPure ${ }^{\mathrm{TM}}$ DNA Purification Kit (Epicentre, Madison, WI, USA). The $16 \mathrm{~S}$ rDNA gene regions V3 to V4 were amplified by PCR using the Bakt_341F/Bakt_805R primers [62]. Primers were barcoded as described by the manufacturer for the Illumina MiSeq sequencing technology. For the fungi analysis, primers ITS1F/ITS2 were used. Overall, 181 samples, corresponding to the fermentation of 7 grapes cultivars, including Cabernet Sauvignon, Carignan, Chardonnay, Merlot, Pinot, Syrah, and S. Blanc, were processed. Samples collected at the beginning of the fermentation (day 0 ) and after 7 days were subjected to extraction and sequencing of DNA.

Processing of the $16 \mathrm{~S}$ rDNA Amplicon Sequences Data Corresponding to Spontaneous Fermentation Samples

Processing of the 16S rDNA amplicon sequences was conducted with the methodology followed by Franco et al., (2020) [60]. Briefly, the reads from fermentation samples were quality trimmed with Trimmomatic (version 0.36), and any reads with lengths less than 36 bp were removed [63]. Primer sequences were removed using MacQIIME 1.9.120150604 [64]. The reads were merged using fastq-join with the default parameters [65], and merged reads with Phred quality scores less than 20 were removed. VSearch [66] was used to de-replicate the sequences and remove singletons, sort them by sequence abundance, and cluster the sequences at $97 \%$. The most abundant read from each cluster was selected as the cluster centroid and, with VSearch, chimeras were removed from the list of centroids. The remaining sequences served as a set of representative sequences. The read sequences were mapped to the representative sequences to generate the orthologue taxonomic units (OTUs) data. Taxonomy was assigned to the OTUs using the SILVA (version 128) database $[67,68]$. The OTUs that represented less than $0.005 \%$ of the total sequences were removed, along with those that corresponded to chloroplasts and/or mitochondria. MacQIIME 1.9.1-20150604 was used to calculate the alpha diversity metrics, including phylogenetic diversity (PD), Chao1, and the observed OTUs count to assess the sampling depth. PYNAST was used to align the sequences using the SILVA (version 128) core alignment sequences [69]. Based on the resulting alpha diversity plots, a rarefaction level of 20,000 sequences per sample was selected.

ITS Amplicon Sequences Data Processing, Corresponding to Grape Juice Fermentation Samples

Regarding the fungal analysis, the readings that were below $36 \mathrm{bp}$ were discarded in the analysis. Regarding the forward and backward reads, they were fused with an overlap of $50 \mathrm{bp}$, eliminating the quality reads less than 20 and 200 bases in length. For reading clipping, an ITS Extractor (ITSx; Bengtsson-Palme et al., 2013) was used. All the results obtained were processed as described for the bacterial analysis. However, the UNITE database (https:/ / unite.ut.ee/repository.php accessed on 20 November 2016) was used for the taxonomic assignment. For this analysis, OTUs smaller than $0.005 \%$ of the total sequences were discarded. Samples were rarefied to 7000 reads for Beta and Alpha diversity analysis for samples containing more than 1000 reads.

\subsection{Alcohol Production by the Selected Non-Saccharomyces Isolates}

The defined medium was fermented with selected isolates $(75 \mathrm{~g} / \mathrm{L}$ glucose, $75 \mathrm{~g} / \mathrm{L}$ fructose, $3 \mathrm{~g} / \mathrm{L}$ tartaric acid, and $6.76 \mathrm{~g} / \mathrm{L}$ yeast nitrogen base, at a $\mathrm{pH}$ of 3.5) [70]. Strains were screened in single cultures in a $250 \mathrm{~mL}$ sterile fermentation flask provided with airlocks. The inoculum was prepared with overnight yeast cultures $\left(18-24 \mathrm{~h}\right.$ at $\left.25^{\circ} \mathrm{C}\right)$, centrifuged, and washed twice with peptone water $(0.01 \%)$. The resulting pellets were re-suspended in the same solution. The inoculate were transferred to the defined medium 
to $5 \log \mathrm{CFU} / \mathrm{mL}$ and incubated at $25^{\circ} \mathrm{C}$ for 4 days. Samples were collected and analyzed for $\mathrm{pH}$ and sugar and ethanol concentrations as described in Section 2.2.3. Inoculations with a commercial S. cerevisiae (Actiflore BO213, Laffort, Bourdeux, France) were used as the control.

\subsection{Non-Saccharomyces Isolates Sequential Fermentations with S. cerevisiae in Carmenere Grape Juice}

Two selected non-Saccharomyces yeasts belonging to the Candida genera isolate were evaluated in sequential fermentation with the commercial $S$. cerevisiae yeast in Carménère grape juice (Santa Emiliana Winery, Chile). This grape juice was selected because is the signature wine of Chile [71] and, therefore, there is an industrial interest to contribute with unique attributes to the wine variety that might be given by non-Saccharomyces yeasts. The grape juice's YAN was adjusted to $250 \mathrm{mg} / \mathrm{L}$ and $35 \mathrm{mg} / \mathrm{L}$ of free $\mathrm{SO}_{2}$ was added using a sodium metabisulphite solution ( $2 \%$, Sigma Aldrich), and the $\mathrm{pH}$ was adjusted to 3.55. Sequential fermentations were carried out in 4 L bioreactors (Applikon Biotechnology, Dover, NJ, USA) at $25^{\circ} \mathrm{C}$ and $100 \mathrm{rpm}$ for 7 days. The grape juice was aeriated for $20 \mathrm{~min}$ before fermentation at an airflow of $0.05 \mathrm{~mL} / \mathrm{min}$. Overnight non-Saccharomyces yeast cultures (6 $\log \mathrm{CFU} / \mathrm{mL}$ ) were inoculated into the grape juice and allowed to grow. After 3 days, the commercial S. cerevisiae yeast was inoculated $(6 \log \mathrm{CFU} / \mathrm{mL})$. A pure culture fermentation with the commercial $S$. cerevisiae (Laffort) strain was used as a control. Samples were collected daily for chemical and microbial analysis as described in Sections 2.2.2 and 2.2.3.

\subsection{Statistical Analysis}

Experiments were carried out in triplicate for two independent assays. Log microbial plate counts and measured concentrations of organic acids, sugar, ethanol, and glycerol were analyzed using the analysis of variance (ANOVA) procedure with Duncan's multiplerange test with the Statistical Analysis Systems version 9.0 software (SAS Institute, Cary, NC, USA).

\section{Results and Discussion}

\subsection{Spontaneous Fermentation}

The microbiota present in the fresh grape juice and after the 7-day fermentation were characterized. Grape samples were collected in April-May 2013, during the grape harvest in Chile, from Palo Alto Winery (Maule, Chile) and then transported to the experimental laboratory in Santiago (Chile). Upon arrival, grapes were separated from leaves and stems, and processed into juice. The juice was allowed to ferment spontaneously for 7 days.

Fresh grape juice contained $141 \pm 0.03$ to $138 \pm 0.07 \mathrm{~g} / \mathrm{L}$ glucose, $118.1 \pm 0.05$ to $120 \pm 0.3 \mathrm{~g} / \mathrm{L}$ fructose, and $0.01 \pm 0.00$ to $0.03 \pm 0.00 \mathrm{~g} / \mathrm{L}$ glycerol. No ethanol was detected in any of the samples (data not shown). After fermentation (7 days), sugar concentrations were $<2 \mathrm{~g} / \mathrm{L}$, a value at which the fermented grape juice can be considered as dry and stable to further spoilage. Glycerol concentrations ranged from $10.8 \pm 0.03$ to $15.7 \pm 0.02 \mathrm{~g} / \mathrm{L}$, with the higher concentration achieved for the Pinot spontaneous fermentation. Finally, the ethanol concentration ranged from $13.8 \pm 0.03$ to $14.2 \pm 0.01 \mathrm{~g} / \mathrm{L}$, with the higher concentration for the Merlot fermentation (data not shown). As expected, LAB and yeast counts increased as the fermentation proceeded (Table 1). LAB final counts after 7 days of fermentation ranged between $6.33 \pm 0.01$ and $7.70 \pm 0.03 \log$ CFU / mL, while yeasts populations reached between $7.39 \pm 0.31$ and $7.81 \pm 0.11 \log \mathrm{CFU} / \mathrm{mL}$, depending on the grape cultivar. 
Table 1. Changes in lactic acid bacteria and yeast population observed during the spontaneous grape juices fermentation.

\begin{tabular}{ccccc}
\hline \multirow{2}{*}{ Grape Variety } & \multicolumn{2}{c}{ LAB $(\log$ CFU/mL) } & \multicolumn{2}{c}{ Yeast $(\log$ CFU/mL) } \\
\cline { 2 - 5 } & D0 & D7 & D0 & D7 \\
\hline C. Sauvignon & $2.13 \pm 0.06$ & $7.80 \pm 0.07$ & $4.81 \pm 0.07$ & $7.81 \pm 0.11$ \\
Carignan & $2.32 \pm 0.05$ & $6.33 \pm 0.01$ & $4.69 \pm 0.08$ & $7.52 \pm 0.23$ \\
Chardonnay & $2.38 \pm 0.08$ & $7.77 \pm 0.16$ & $5.08 \pm 0.00$ & $7.71 \pm 0.05$ \\
Merlot & $1.81 \pm 0.90$ & $7.50 \pm 0.06$ & $5.19 \pm 0.02$ & $7.71 \pm 0.05$ \\
Pinot & $1.69 \pm 0.08$ & $7.59 \pm 0.30$ & $4.63 \pm 0.03$ & $7.39 \pm 0.31$ \\
S. Blanc & $1.72 \pm 0.11$ & $7.35 \pm 0.03$ & $4.75 \pm 0.12$ & $7.67 \pm 0.11$ \\
Syrah & $1.82 \pm 0.17$ & $7.70 \pm 0.03$ & $4.89 \pm 0.14$ & $7.60 \pm 0.12$ \\
\hline
\end{tabular}

Values represent mean \pm standard deviations for two independent sets and three replicates $(n=6)$.

\subsection{Yeasts Diversity during the Spontaneous Fermentation}

A great diversity of native yeasts was observed (Figure 2). Non-Saccharomyces yeasts were abundant in fresh grape juice (day 0 of fermentation), with Pinot, S. Blanc, and C. sauvignon showing the greatest diversity among all grape cultivars. Similarly to our results, Jara et al., (2016) reported several non-Saccharomyces yeasts in fresh grape juices from different cultivars in the Maule region (Chile), in which Metschnikowia, Hanseniaspora, and Rhodotorula were the most abundant [51]. Although these genera were also observed in our study, they were not the most abundant in all the grape cultivars we studied, in which a greater diversity was observed.

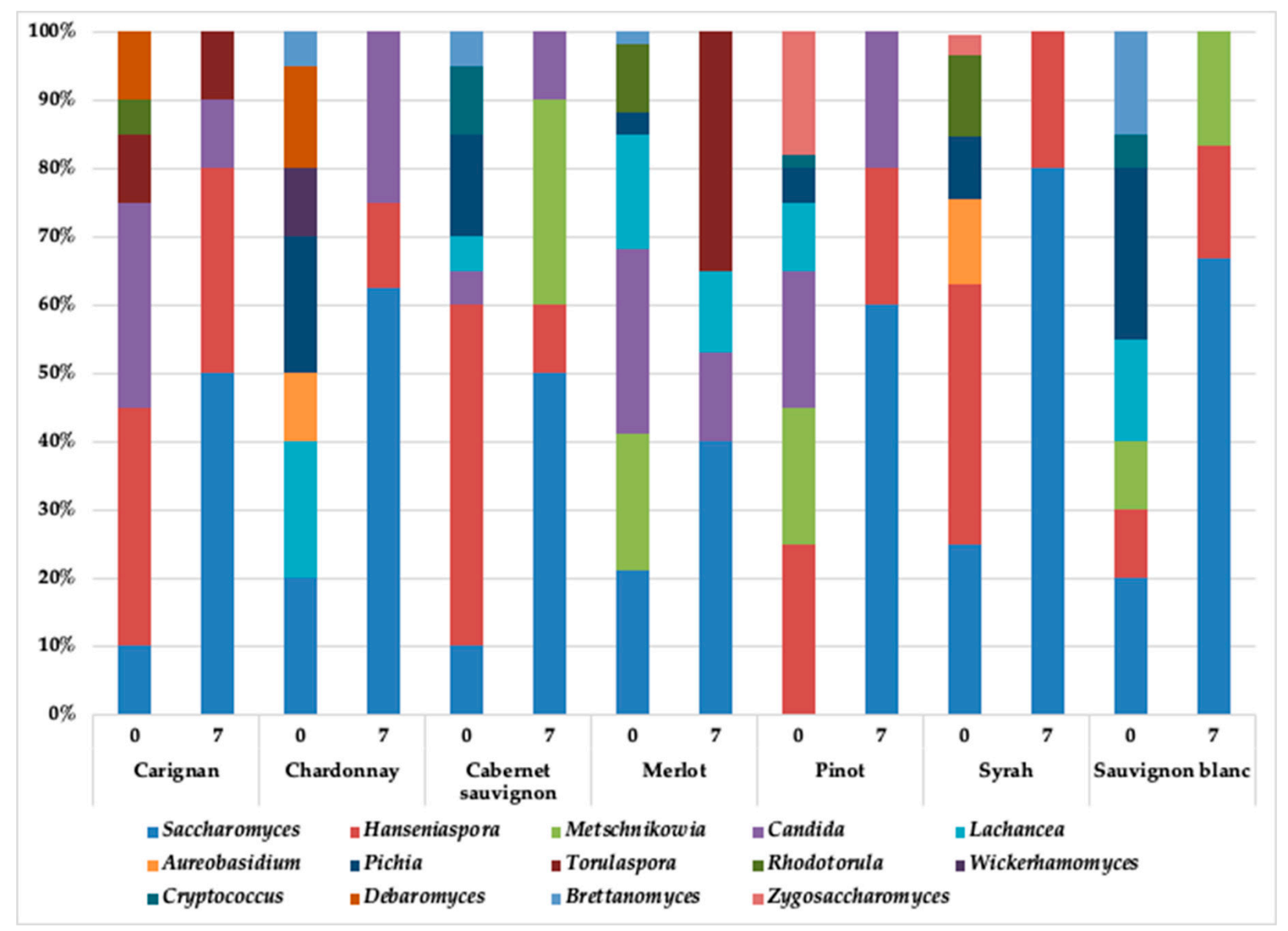

Figure 2. Results of the ITS gene amplicon sequencing data analysis for fresh and fermented grape juice samples collected on days 0 and 7 of fermentation. Data are presented by grape cultivar. 
These difference might be attributed to the different grape cultivars characterized in the studies, while Jara et al., (2016) characterized yeast presence in Petit Verdot, Alicante Bouschet, Torontel, and Mencia cultivars, while we focused on the characterization of Cabernet Sauvignon, Carignan, Chardonnay, Merlot, Pinot, Syrah, and S. Blanc, which present different intrinsic factors, such as nutrient content, that might influence the microbial colonization as well the agronomic practices followed [72-74]. In addition, environmental factors, such as rainfall, have been also associated to difference in yeast abundancy $[9,11,51]$. In grapes, the microbial load is reduced as rainfall increases due to a microorganism washout. According to the Environmental Ministry of Chile, no rainfall was reported between March and April 2013, the year during which grape samples were collected for our study. While precipitations were reported for the same months in 2015, during which the study of Jara et al., (2016) took place [75].

The geographical location of the vineyard from which samples were collected might also influence the microbial composition [76]. The Palo Alto vineyard is located in one of the central valleys of Chile $\left(35^{\circ} 26^{\prime} \mathrm{S} 71^{\circ} 40^{\prime} \mathrm{W}\right.$, Chile, Figure 1), at about 100 m.a.s.l and has a temperature ranging from 17 to $23{ }^{\circ} \mathrm{C}$ during the harvest season [77]. Given these conditions, and that the grape vines were collected towards the end of the harvest season, they might have had a greater sugar content, which favors the establishment of a diverse microbial population [78]. In addition, the vinery location is characterized by torrid weather with almost no rainfall from October to March, and rainy winters from April to September. However, the entire region is affected by the "La Niña" climatic event, which operates as an eventual factor that specifically affects the climatic conditions associated with rains causing periodic drought. These conditions not only affect the quality and production of the vineyards, but it is also very possible that they affect the types and proportions of native microorganisms in the grapes [75].

As the spontaneous fermentation progressed, most of the non-Saccharomyces yeasts decreased their presence in the must, even disappearing on day 7. This might be explained by its low resistance to the harsh environmental conditions, characterized mostly by the lack of nutrients and high ethanol concentrations $[23,24,26,27,49]$. On the contrary, the Saccharomyces genera that showed a relative abundance from $10 \%$ to $40 \%$ at day 0 take advantage of these conditions, and therefore become dominant.

In spite of this dominance, some non-Saccharomyces yeasts genera were also detected after 7 days of fermentation: Hansenioaspora, Metschnikowia, Candida, Lachancea, and Torulaspora (Figure 2). The yeast distribution observed was associated with the type of grape juice studied. For example, in the case of the genus Hanseniaspora, it was detected in all the grape juices evaluated except in Merlot. Torulospora was detected in Carignan and Merlot, while Metshnikowia was detected in C. Sauvignon, Sauvignon Blanc, and Pinot. In the case of the Candida genus, its presence was found in C. Sauvignon, Merlot, Pinot, and Chardonnay. The presence of these non-Saccharomyces genera on day 7 of spontaneous fermentation presupposes the peculiarity of being resistant to ethanol. Although non-Saccharomyces yeasts have low tolerance to ethanol, our results show that some can be isolated once the alcoholic fermentation was completed (Table 2). Catrileo, Acuña-Fontecilla, and Godoy (2020) reported that T. delbrueckii YCPUC10, isolated from C. Sauvignon grape juice, was able to persist with ethanol levels of about $11 \%$ as the result of an adaptative metabolism [79]. Furthermore, certain non-Saccharomyces are able to increase their ethanol tolerance by producing succinic acid [80] and this might be the case of the Metschnikowia, Torulospora, Hanseniospora, and Candida spp. detected at the end of the fermentation. However, more studies are necessary to fully characterize the capability in the isolated strains.

These results are interesting, since they would allow us to investigate local (terroirspecific) strains that are able to positively impact the sensory profiles of wines, probably in co-fermentations with $S$. cerevisiae, or even in monocultures. Increases in ethanol resistance might be advantageous in order to allow for the production of other metabolites associated to the non-Saccaromyces yeasts. For example, Metschnikowia spp. is capable of the formation of esters, monoterpenoids, and higher alcohols due to its $\beta$-glucosidase activity, which can 
improve the aromatic profile in wines [81,82]. Torulaspora delbrueckii has been associated to the production of mannoproteins and aroma compounds that increase the mouthfeel in red wines $[83,84]$.

Table 2. Identification of the yeast species found on day 7 of spontaneous fermentation. These species were obtained from isolated colonies that presented a different and unique morphology, which was later identified with $26 \mathrm{~S}$ rRNA sequences.

\begin{tabular}{|c|c|}
\hline Grape Variety & Yeast Identification (\% Abundance) \\
\hline Carignan & $\begin{array}{l}\text { Hanseniaspora uvarum (40) } \\
\text { Saccharomyces cerevisiae (20) } \\
\text { Starmerella bacillaris (20) } \\
\text { Lachancea thermotolerans (20) }\end{array}$ \\
\hline Chardonnay & $\begin{array}{l}\text { Aureobasidium pullulans (16) } \\
\text { Candida oleophila (12) } \\
\text { Candida stellate (12) } \\
\text { Starmerella bacillaris (12) } \\
\text { Hanseniospora uvarum (12) } \\
\text { Lachancea thermotolerans (12) } \\
\text { Saccharomyces cerevisiae (24) }\end{array}$ \\
\hline Cabernet Sauvignon & $\begin{array}{c}\text { Candida stellata (24) } \\
\text { Hanseniaspora uvarum (20) } \\
\text { Torolaspura delbrueckii (7) } \\
\text { Metchinoskowia pulcherrima (21) } \\
\text { Saccharmyces cerevisiae (28) }\end{array}$ \\
\hline Merlot & $\begin{array}{c}\text { Candida stellata (15) } \\
\text { Starmerella bacillaris (15) } \\
\text { Candida oleophila (15) } \\
\text { Lachancea thermotolerans (25) } \\
\text { Saccharomyces cervisiae (15) } \\
\text { Torulaspora delbrueckii (15) }\end{array}$ \\
\hline Pinot & $\begin{array}{l}\text { Hanseniospora uvarum (20) } \\
\text { Metschnikowia pulecherrima (20) } \\
\text { Saccharomyces cerevisiae (60) }\end{array}$ \\
\hline Syrah & $\begin{array}{l}\text { Aureobasidium pullulans (17) } \\
\text { Hanseniospora uvarum (17) } \\
\text { Saccharomyces cerevisiae (66) }\end{array}$ \\
\hline Sauvignon blanc & $\begin{array}{l}\text { Lachancea thermotolerans (14) } \\
\text { Metschnikowia pulcherrima (28) } \\
\text { Saccharomyces cerevisiae (58) }\end{array}$ \\
\hline
\end{tabular}

A yeast-like fungus (Aureobasidium) was detected with an abundance of approximately $10 \%$ in the fresh grape juice samples. Species of Aureobasidium have been reported as able to survive in grape juice $[23,85]$ and have been isolated from different grape cultivars in the Maule region [51], so their presence is not unusual. However, in terms of their presence at the end of the fermentation process, this might indicate a contamination problem $[23,86]$.

The culture-dependent analysis showed a diverse make up of yeasts, although less varied than the molecular analysis. Similarly to what was observed with the molecular analysis, the dominant yeast genus in 7-day fermented grape juice was Saccharomyces $(39 \%)$ (Figure 3). However, a significant diversity of non-Saccharomyces yeasts was also isolated. The most abundant yeasts were Hanseniospora (13\%), followed by Candida (11\%), Metchinoskowia (10\%), Lachancea (10\%), Starmerella (7\%), and Torolospura $(5 \%)$. The yeastlike fungus Aureobasidium was also isolated (5\%). The yeast-like fungus has also been isolated from spontaneous Grignolino grape fermentation [87]; therefore, their presence is not unusual. 


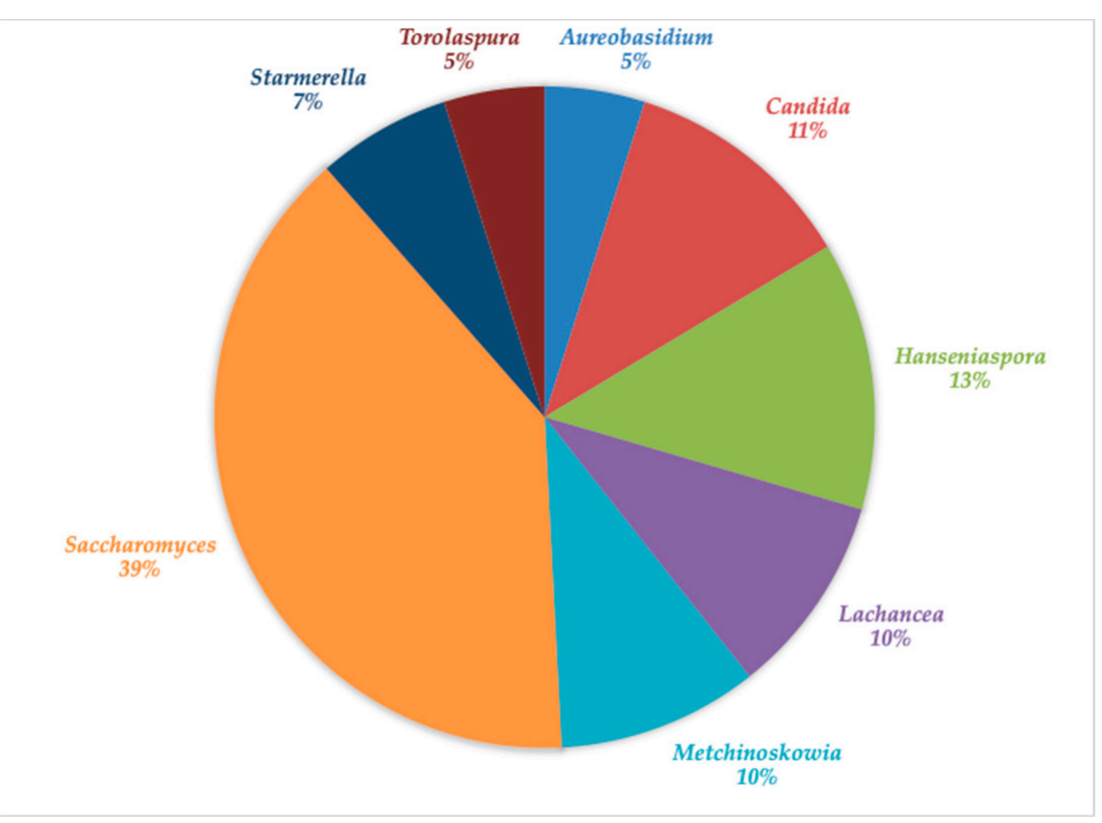

Figure 3. Estimated distribution of yeast species isolated from the spontaneous grape fermentations tested based on morphology. The colonies isolated were identified based on the 26S rRNA sequences.

Table 2 shows an abundance of yeasts according to species found in the different musts evaluated; L. thermotolerans, M. pulcherrima, H. uvarum, T. delbrueckii, C. oeophila, Starmerella bacillaris (formerly called C. zemplinina), C. stellata, and A. pulluans. The Shannon diversity index calculated for each grape cultivar ranged from 0.17 to 1.15 (data not shown), evidencing, as reported previously, the diversity of yeast within different cultivars even if they are cultivated in the same vineyard [87].

Similarly to the molecular analysis, single species distribution was also variable: T. delbrueckii was only isolated from C. Sauvignon fermentations; A. pullulans from Chardonnay and Syrah; C. oleophila from Chardonnay and Merlot; C. stellata from Chardonnay, C. Sauvignon, and Merlot; St. bacillaris from Carignan, Chardonnay, and Merlot; M. pulcherrima from C. Sauvignon, Pinot, and S. blanc; H. uvarum from Carignan, C. Sauvignon, Pinot, and Syrah; and L. thermotolerans from Carignan, Chardonnay, Merlot, and S. blanc (Table 2). The uneven distribution of yeast species from a single vineyard might be explained by the many microclimates created within the vineyard $[11,87]$. The non-Saccharomyes microbiota was dominated by L. thermotolerans, H. uvarum, and M. pulcherrima, representing $54 \%$ of the yeast population. In correlation to the molecular characterization, after 7 days, the Merlot fermentations showed the greatest isolate diversity. On the other hand, as expected, S. cerevisiae was isolated transversally in almost all the fermentations, showing the higher numbers of isolates across all grape cultivar samples (Table 2, Figure 3).

The diversity observed in this study is in line with that previously reported for spontaneous grape juice fermentations $[10,11,25-27,49,87]$, in which a number of nonSaccharomyces yeast were detected and/or isolated primarily at the early stages of the fermentation process. In our study, non-Saccharomyces yeasts were also isolated after 7 days of fermentation, which indicates that the species have a certain tolerance to the ethanol concentration (13.08 \pm 0.03 to $14.2 \pm 0.11 \% v / v)$ and nutrient deprivation (glucose and fructose: $1.70 \pm 0.05$ to $2.12 \pm 0.05 \mathrm{~g} / \mathrm{L}$, respectively) conditions reached in 7 days of the spontaneous fermentations (data not shown). Given the scare information available regarding yeast diversity from Chilean grape varieties and terroirs, the results obtained contribute to broaden the literature in this topic. Furthermore, with the aim of creating signature and different wines, wineries are exploring the possibility of spontaneous and biodynamic fermentation [88], and therefore, the characterization of the natural microflora 
and its intrinsic dynamic during the alcoholic fermentation might be crucial to determine correct process that end in stable wines.

\subsection{Lactic Acid Bacteria Diversity during the Alcoholic Fermentation}

$\mathrm{LAB}$ compose a part of the microbiota found in grapes and winery equipment; they are important in the winemaking process, but their identification and isolation have been limited mostly to grapes and during malolactic fermentation [89]. In our study, the impact of the alcoholic fermentation and the LAB diversity was studied. Five genera were detected in the fresh and fermented grape juices (Figure 4). In fresh grape juice, the dominant genus was Leuconostoc, followed by Lactobacillus, Lactococcus, Pediococccus, and Weisella. Recently, Kačániová et al., (2020) studied the LAB composition in 10 different grape cultivars (grapes, grape juice, and wine), including Pinot, C. Sauvignon, and Merlot, and reported a similar genera make-up, with Lactobacillus as the dominant genera, followed by Leuconostoc [90].

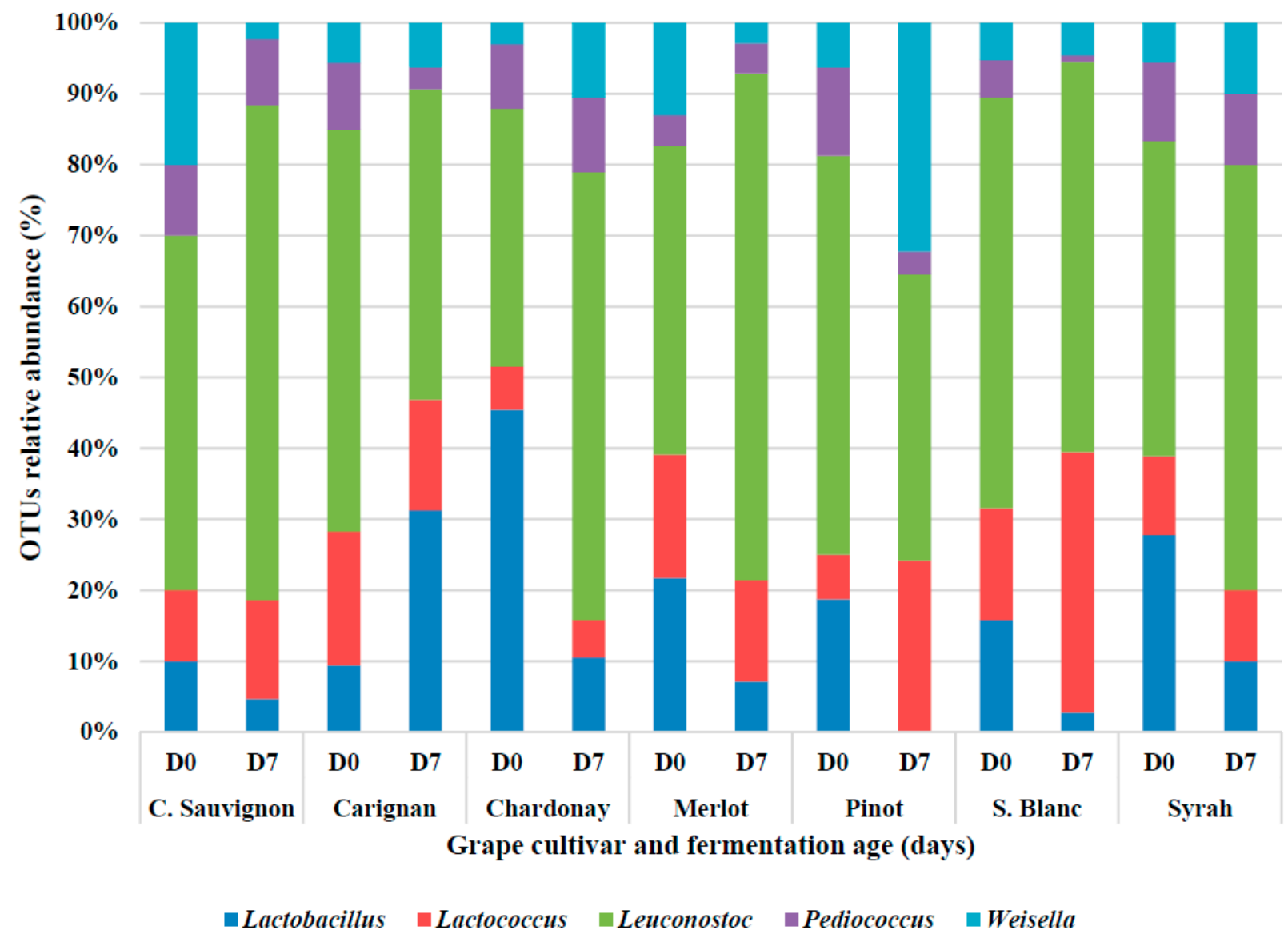

Figure 4. Results of the $16 \mathrm{~S}$ rRNA gene amplicon sequencing data analysis for the fresh and fermented grape juices collected at days 0 and 7 of the fermentation. Data are presented by grape cultivar.

In spontaneous fermentations, the bacterial diversity is more abundant than in an inoculated process [48]; however, in our study, the alcoholic fermentation negatively affected the LAB abundance, and after 7 days, Lactobacillus and Pediococcus decreased significantly (Figure 4). Reduction of LAB populations is expected as the alcoholic fermentation proceeds, the environment becomes richer in ethanol, and sugars are depleted [20]. Although these changes occurred after 7 days of fermentation, Leuconostoc remained as the dominant genera. According to Piettet et al., (2011), LAB resistance to ethanol is not strain dependent, and among the $61 \mathrm{LAB}$ tested by the authors, all showed great resistance to ethanol concentrations ranging from $0.5 \%$ to $14 \%(v / v)$ [91]. This suggests that an important factor for the reduction in LAB diversity during alcoholic diversity might be the depletion of sugars 
(20) associated to other factors such as the phenolic content [92]. Similarly to the yeast diversity, the grapes varieties, cultivation conditions, climate, and geographical location of the vineyard affect the LAB composition. For example, Berbegat et al., (2020) reported that the LAB consortium of Uva di Troi grape juices spontaneously fermented, and was composed of Oenococcus, Acetobacter, Proponibacterium, and Gluconbacter as the dominant bacteria. Lactobacillus was also detected but in lower abundance (10\%) [48].

For the culture-dependent analysis, the colonies observed in MRS agar plates were grouped according to their morphology, and these initial observations allowed for the classification of the 58 isolates in three different clusters. Molecular 16S rRNA identification showed that the LAB isolates belonged to the Leuconostoc and Lactobacillus genera with three species identified (Table 3). The most abundant LAB was Leuconostoc mesenteroides, which was isolated from all fresh and fermented grape juice, while Fructilactobacillus fructivorans and Lactobacillus delbrueckii ssp delbrueckii were only isolated from the Carignan and Pinot fresh grape juice, respectively. Berbegal et al., (2019) reported that a heterogenous consortia of LAB are present in spontaneous most fermentations [48]. However, in our study, we were able to observe a lesser diversity, represented mostly by Firmicutes, with the Leuconostoc genera predominant. López-Seijas et al., (2020) reported that Lactobacillus is the prominent bacteria in Albariño grapes, with L. plantarum as the dominant species [93]. In our study, the most abundant species was L. mesenteroides isolated at diverse time points in the alcoholic fermentation (Table 3). The lesser diversity might indicate that the spontaneous alcoholic fermentation negatively influences the LAB consortia. This suggests that LAB make-up in the grapes studied shows little tolerance to the conditions reached as ethanol is produced, sugars are depleted, and yeast populations increase. Mendoza, Manc de Nadra, and Farías (2010) reported that, besides the typical conditions achieved during alcoholic fermentation, inhibition might be attributed to the ability of $S$. cerevisiae to produce peptides with inhibitory effects [94]. However, the fact that we were not able to isolate more $\mathrm{LAB}$ once the alcoholic fermentation ended, does not indicates that they are not present. According to Capozzi et al., (2021), the concentration of LAB increases 10 to 15 days after the alcoholic fermentation is completed [95]. In our study, we did not consider keeping the fermented grape juice for a MLF fermentation, at which point dormant bacteria might be able to establish. Furthermore, for the culture-dependent method, the medium used to isolate the LAB did not have any enrichment, and the isolation was based in a morphological similarity among the observed colonies, which might also affect the diversity of the isolated species. Thus, more studies are necessary to complete the diversity of LAB during the spontaneous alcoholic and malolactic fermentations of these Chilean grape cultivars.

Table 3. Identification of the $\mathrm{LAB}$ colonies isolated from the spontaneous grape juice fermentations. Colonies piqued represented a unique colony morphology. The colonies isolated were identified based on the 16S rRNA sequences.

\begin{tabular}{ccc}
\hline Grape Variety (No. of Colonies) & Isolation Time Point (Day) & LAB Identification \\
\hline C. Sauvignon (6) & 0,7 & \\
Carignan (4) & 0,7 & \\
Chardonnay (3) & 0,7 & Leuconostoc mesenteroides \\
Merlot (6) & 0,7 & \\
Pinot (11) & $0,3,7$ & \\
S. Blanc (17) & $0,3,7$ & Fructilactobacillus fructivorans \\
Syrah (3) & 0,7 & Lactobacillus delbrueckii ssp delbrueckii \\
Carignan (3) & 0 & 0 \\
Pinot (5)
\end{tabular}

An important trait of LAB is the production of organic acids such as lactic and acetic acids. Once the fermentation was stopped, lactic acid reached values ranging from $1.12 \pm 0.01$ to $1.18 \pm 0.02 \mathrm{~g} / \mathrm{L}$, with the highest concentration associated with the $\mathrm{S}$. Blanc fermentation (Table 4); these values are in line with those previously reported for spontaneous wine fermentations [20]. The higher acetic acid concentration was observed 
for the Pinot fermentation, which reached $1.17 \pm 0.01 \mathrm{~g} / \mathrm{L}$, while the rest of the fermentations remained at $1.10 \mathrm{~g} / \mathrm{L}$ or below. Acetic acid production is expected not only from the native yeasts, but also from the heterofermentative LAB. On the other hand, malic acid decreased in comparison with the initial values, and small amounts were detected once the alcoholic fermentation ended, with values ranging from 0.04 to $0.08 \mathrm{~g} / \mathrm{L}$. Ripe grapes might contain between 2 and $6.5 \mathrm{~g} / \mathrm{L}$ of malic acid; therefore, the presence of small amounts of the acid in the fermented grape juices might be also attributed to the presence of LAB with malolactic activity capacity [20]. Among the isolated species, Leuconostoc mesenteroides and Lactobacillus delbrueckii have been reported as positive for malolactic activity; therefore, their presence might explain the low malic acid values encountered. The degradation of malic acid in wines results in a decrease in acidity, which favors the overall flavor. In our study, the Carignan and Pinot fermentations resulted in a $\mathrm{pH}$ about 0.5 units above the other fermentations (data not shown), which correlates with the presence of these malolactic bacteria (Table 3, Figure 3).

Table 4. Organic acids produced after 7 days of spontaneous fermentation.

\begin{tabular}{ccccccc}
\hline \multirow{2}{*}{ Grape } & \multicolumn{2}{c}{ Lactic Acid (g/L) } & \multicolumn{2}{c}{ Acetic Acid (g/L) } & \multicolumn{2}{c}{ Malic Acid (g/L) } \\
\cline { 2 - 7 } & D0 & D7 & D0 & D7 & D0 & D7 \\
\hline C. Sauvignon & ND & $1.15 \pm 0.01^{\mathrm{a}}$ & ND & $1.07 \pm 0.03^{\mathrm{a}}$ & $2.50 \pm 0.01^{\mathrm{a}}$ & $0.04 \pm 0.01^{\mathrm{a}}$ \\
Carignan & ND & $1.18 \pm 0.04^{\mathrm{a}}$ & $0.03 \pm 0.01$ & $1.10 \pm 0.05^{\mathrm{b}}$ & $2.61 \pm 0.01^{\mathrm{b}}$ & $0.04 \pm 0.01^{\mathrm{c}}$ \\
Chardonnay & ND & $1.12 \pm 0.01^{\mathrm{a}}$ & ND & $1.06 \pm 0.02^{\mathrm{a}}$ & $2.32 \pm 0.01^{\mathrm{c}}$ & $0.08 \pm 0.02^{\mathrm{b}}$ \\
Merlot & ND & $1.14 \pm 0.03^{\mathrm{a}}$ & ND & $1.05 \pm 0.01^{\mathrm{a}}$ & $3.13 \pm 0.01^{\mathrm{e}}$ & $0.06 \pm 0.02^{\mathrm{d}}$ \\
Pinot & $0.08 \pm 0.03^{\mathrm{a}}$ & $1.17 \pm 0.04^{\mathrm{b}}$ & ND & $1.17 \pm 0.04^{\mathrm{b}}$ & $2.37 \pm 0.03^{\mathrm{c}}$ & $0.06 \pm 0.01^{\mathrm{c}}$ \\
S. Blanc & $0.03 \pm 0.02^{\mathrm{b}}$ & $1.13 \pm 0.02^{\mathrm{a}}$ & ND & $1.05 \pm 0.03^{\mathrm{a}}$ & $2.85 \pm 0.01^{\mathrm{d}}$ & $0.07 \pm 0.02^{\mathrm{b}}$ \\
Syrah & ND & $1.12 \pm 0.05^{\mathrm{a}}$ & ND & $1.06 \pm 0.03^{\mathrm{a}}$ & $2.82 \pm 0.01^{\mathrm{d}}$ & $0.08 \pm 0.01^{\mathrm{b}}$ \\
\hline
\end{tabular}

Values represent mean \pm standard deviations for two independent sets and three replicates $(n=6)$. Different lower-case superscript letters within columns indicate significant differences $(p<0.05)$.

\subsection{Fermentative Profile of Selected Yeast Isolates}

With the aim to better characterize the yeast diversity isolated from the different grape varieties, selected non-Saccharomyces yeast isolates were screened for sugar consumption and ethanol yield under limited aerobic conditions over four days of fermentation. Sugar utilization ranged between $14.9 \%$ and $63.5 \%$ and was strain dependent (Table 5). Ethanol yields, defined as the amount of ethanol produced per gram of consumed sugar, was estimated to identify strains that utilized carbon sources to metabolites different than ethanol. The ethanol yield was isolate specific and ranged from 0.18 to 0.51 , while the commercial strain showed a yield of 0.44 (which is expected for the strain). Corresponding to the difference between the control yield, the isolates were grouped as low, medium, and high ethanol producers. Low producers were defined as those isolates that produced equal or less than $0.35 \mathrm{~g}$ ethanol/g glucose, medium as those between 0.39 and $0.45 \mathrm{~g}$ ethanol/g glucose, and yields higher than $0.45 \mathrm{~g}$ ethanol/g glucose were categorized as high producers (Table 5).

One C. oleophila strain showed the lowest ethanol yield, interestingly associated to the highest sugar consumption. Non-Saccharomyces yeast, in contrast to $S$. cerevisiae, divert the flux of carbon for the production of ethanol to by-products and biomass synthesis [20]. Furthermore, under limited air conditions, a wide array of secondary products are formed [20], which may in part explain the low ethanol yields. One M. pulcherrima and three out of five H. uvarum strains showed low ethanol yields ranging from 0.30 to 0.35 . In Contreras et al., (2015), strains from the same genus showed different ethanol yields, indicating that ethanol production in non-Saccharomyces yeasts was strain specific [20]. Some L. thermotolerans, T. delbrueckii, and C. oleophila strains showed ethanol yields similar or higher than S. cerevisiae, and therefore were labeled as medium and high ethanol producers, respectively. The first two have been studied as suitable for use in beer and wine fermentation with the trait of reducing the ethanol content [20] and contributing specific volatile profiles [20]. 
Table 5. Ethanol yield and sugar utilization of non-Saccharomyces yeast isolates.

\begin{tabular}{|c|c|c|c|c|}
\hline Yeast Isolate & Grape Source & $\begin{array}{c}\text { Ethanol Yield } \\
\text { (g Ethanol/g Glucose) }\end{array}$ & $\begin{array}{l}\% \text { Glucose } \\
\text { Consumed }\end{array}$ & Category \\
\hline Candida olepohila-1 & Chardonnay & 0.18 & $63.50 \%$ & \multirow{11}{*}{ LOW } \\
\hline Candida oleophila-2 & Merlot & 0.23 & $50.90 \%$ & \\
\hline Hanseniaspora uvarum-1 & Carignan & 0.3 & $23.40 \%$ & \\
\hline Metschnikowia pulcherrima-1 & C. Sauvignon & 0.31 & $22.70 \%$ & \\
\hline Hanseniaspora uvarum-2 & Chardonnay & 0.33 & $20.50 \%$ & \\
\hline Hanseniaspora uvarum-3 & C. Sauvignon & 0.33 & $20.50 \%$ & \\
\hline Metschnikowia pulcherrima-2 & Pinot & 0.33 & $21.20 \%$ & \\
\hline Metschnikowia pulcherrima-3 & Pinot & 0.33 & $37.60 \%$ & \\
\hline Hanseniaspora uvarum-4 & Pinot & 0.34 & $21.60 \%$ & \\
\hline Metschnikowia pulcherrima-4 & S. blanc & 0.35 & $42.70 \%$ & \\
\hline Metschnikowia pulcherrima-5 & S. blanc & 0.35 & $41.60 \%$ & \\
\hline Starmerella bacillaris & Carignan & 0.39 & $35.00 \%$ & \multirow{10}{*}{ MEDIUM } \\
\hline Candida stellata & Chardonnay & 0.4 & $42.00 \%$ & \\
\hline Hanseniaspora uvarum-5 & Syrah & 0.4 & $23.70 \%$ & \\
\hline Torulaspora delbrueckii-1 & C. Sauvignon & 0.41 & $41.90 \%$ & \\
\hline Lanchacea thermotolerans-2 & Merlot & 0.43 & $33.70 \%$ & \\
\hline Saccharomyces cerevisiae & Control & 0.44 & $98.50 \%$ & \\
\hline Aureobasidium pullulans-1 & Syrah & 0.45 & $26.40 \%$ & \\
\hline Candida oleophila-3 & Chardonnay & 0.45 & $20.00 \%$ & \\
\hline Lanchacea thermotolerants-2 & Carignan & 0.45 & $32.70 \%$ & \\
\hline Torulaspora delbrueckii-2 & Merlot & 0.45 & $30.70 \%$ & \\
\hline Aureobasidium pullulans-2 & Chardonnay & 0.47 & $27.00 \%$ & \multirow{6}{*}{ HIGH } \\
\hline Hanseniaspora uvarum-6 & C. Sauvignon & 0.48 & $14.90 \%$ & \\
\hline Lanchacea thermotolerans-3 & Carignan & 0.48 & $31.70 \%$ & \\
\hline Lanchacea thermotolerans-4 & Merlot & 0.48 & $29.70 \%$ & \\
\hline Aureobasidium pullulans-3 & Chardonnay & 0.51 & $30.00 \%$ & \\
\hline Lanchacea thermotolerans-5 & S. blanc & 0.51 & $35.30 \%$ & \\
\hline
\end{tabular}

\subsection{Sequential Fermentations}

The yeast species H. uvarum, L. thermotolerans, T. delbrueckii, C. stellata, and M. pulcherrima have been extensively studied for their use in beer, wine, and the elaboration of other fermented foods $[4,20,37,38,41-43,47,84,96-101]$, and their beneficial and negative effects in reducing the alcohol content and contributing to the volatile profile and aroma have been reported previously. In contrast, to our knowledge, little information has been reported the $C$. oleophila strain isolated in our study. Therefore, the yeast was selected for further experimentation, along with $C$. stellata, as a yeast control of the same genera yeast.

Several studies have shown that sequential fermentations initiated by non-Saccharomyces yeasts, and finished by the inoculation of S. cerevisiae, result in wines with desirable and distinct attribute profiles, and with complete fermentations (corroborated by sugar depletion) that result in stable wines $[18,41,70,82,98]$. With this in mind, C. olephila, and C. stellata were fermented in sequence with the commercial S. cerevisiae in Carménère grape juice. The grape variety was selected because it is the signature grape in the Chilean wine industry. The variety disappeared from Europe during the middle of the 19th century and reappeared years later in Chile [71]. The Chilean vineyards in which it is produced have a particular climate and terroir conditions that enable the production of the variety. Moreover, there is an increasing interest of the regional wine industry to give additional attributes to these signature wines, and the use of non-conventional yeast might aid in this purpose.

Figure 5 shows the growth curves obtained for the different isolates and the $S$. cerevisiae strain. As expected, after inoculation, the non-Saccharomyces isolates increased in population, reaching a peak after 2 days; thereafter, the yeast populations decreased significantly to finish at day 7 of fermentation with values below $5.5 \log \mathrm{CFU} / \mathrm{mL}$ for all the strains (Figure 4). The performance observed for the Candida spp. studied here was similar to those reported when native yeasts from spontaneous Pinot Noir, Coralin, Chardonnay, Resi, Petit Arvine, Etmitage, and Gudel fermentations were studied [20]. In contrast, S. cerevisiae, inoculated at day 3 , increased its population for 3 days straight and maintained concentrations above $7 \log \mathrm{CFU} / \mathrm{mL}$ until the end of the fermentation. 


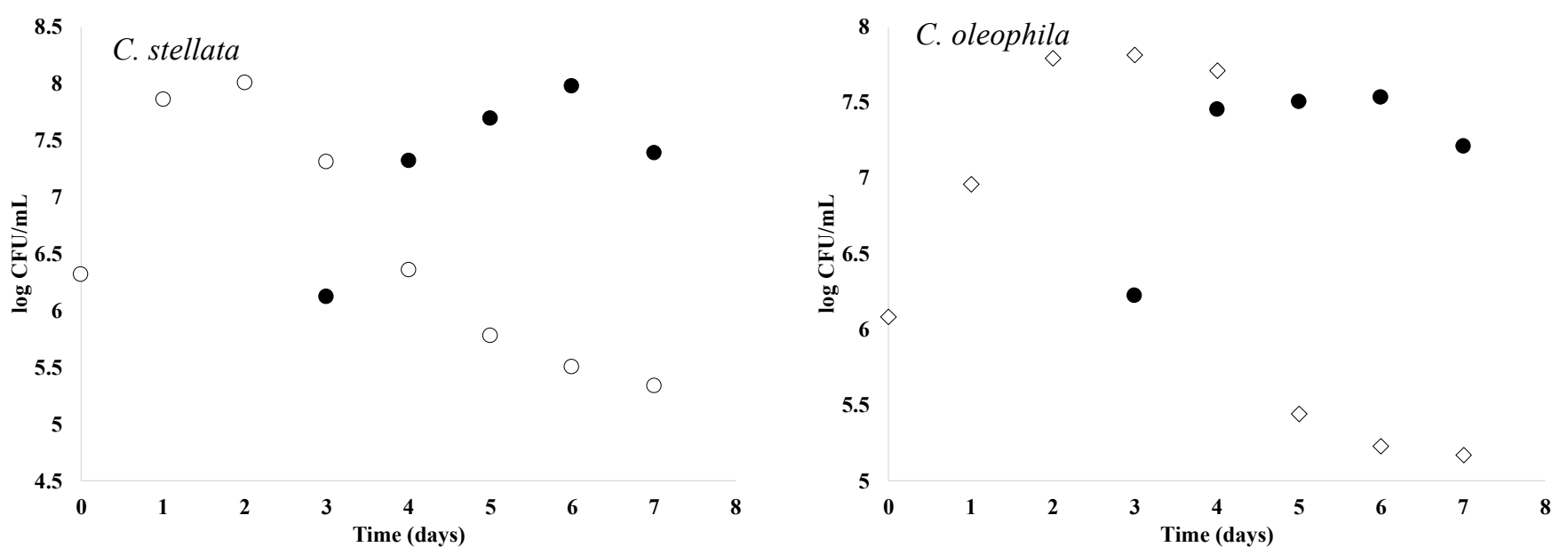

Figure 5. Cell counts in sequential fermentations. $\bullet$ S. cerevisiae; $\circ$ C. stellata; $\diamond$ C. oleophila. Values represent mean \pm standard deviations for two independent sets and three replicates $(n=6)$. Dotted line at day 3 indicates the time point at which S. cerevisiae was inoculated.

The sequential fermentations resulted in lower ethanol concentrations compared to the control fermentation (pure S. cerevisiae inoculation) (Table 6). The average ethanol concentrations were $11.8 \%$ and $12.5 \%$ for C. stellata and C. oleophila, respectively (Table 6). Before the S. cerevisiae inoculation, ethanol content in the $C$. stellata fermentations reached $7.70 \pm 0.05 \%(v / v)$, and $4.55 \pm 0.08 \%(v / v)$ for C. olephila, which correlates with the low ethanol-producing capacity showed by these strains in the defined medium (Table 5). Decreases in the non-Saccharomyces yeast populations were observed once the S. cerevisae inoculum increased in population. These is expected since S. cerevisiae is highly effective in ethanol production, and therefore, the ethanol concentrations in the fermented grape juice increase. Domizzo et al., (2007) reported that among the non-Saccahromyces yeasts characterized in their study, the Candida spp. showed the greatest population reduction once S. cerevisiae was inoculated [102].

Table 6. Sugar utilization and ethanol production observed during the sequential fermentation of C. stellata and C. oleophila with S. cerevisiae.

\begin{tabular}{|c|c|c|c|c|c|c|c|c|c|}
\hline \multirow{3}{*}{ Yeast } & \multicolumn{3}{|c|}{ Glucose (g/L) } & \multicolumn{3}{|c|}{ Fructose (g/L) } & \multicolumn{3}{|c|}{ Ethanol \% $(v / v)$} \\
\hline & \multicolumn{9}{|c|}{ Fermentation Day * } \\
\hline & 0 & 3 & 14 & 0 & 3 & 14 & $\mathbf{0}$ & 3 & 14 \\
\hline C. stellata & $139.2 \pm 0.08^{a}$ & $49.2 \pm 0.01^{\mathrm{a}}$ & $1.90 \pm 0.05^{\mathrm{a}}$ & $110.1 \pm 0.01^{\mathrm{a}}$ & $50.0 \pm 0.01^{\mathrm{a}}$ & $1.00 \pm 0.03^{a}$ & ND & $7.70 \pm 0.05^{\mathrm{a}}$ & $10.8 \pm 0.1^{\mathrm{a}}$ \\
\hline C. oleophila & $140.1 \pm 0.03^{a}$ & $453.1 \pm 0.12^{b}$ & $1.12 \pm 0.01^{b}$ & $110.0 \pm 0.02^{a}$ & $58.2 \pm 0.08^{b}$ & $0.85 \pm 0.07^{\mathrm{a}}$ & ND & $4.55 \pm 0.08^{b}$ & $12.5 \pm 0.1^{b}$ \\
\hline S. cerevisiae & $139.5 \pm 0.03^{\mathrm{a}}$ & $5.13 \pm 0.03^{b}$ & ND & $109.4 \pm 0.01^{\mathrm{a}}$ & $15.31 \pm 0.02^{\mathrm{d}}$ & $1.46 \pm 0.09^{c}$ & ND & $12.8 \pm 0.03^{\mathrm{d}}$ & $13.5 \pm 0.67^{c}$ \\
\hline
\end{tabular}

Values represent mean \pm standard deviations for two independent sets and three replicates $(n=6)$. Different lower-case superscript letters within columns indicate significant differences $(p<0.05)$. * Non-Saccharomyces yeasts were single inoculated at time point 0 , and after 3 days, $S$. cerevisiae was inoculated into the fermentation flasks.

The addition of the $S$. cerevisiae allowed the wine to complete the sugar utilization, and therefore increased the ethanol content, but concentrations were below $14 \%(v / v)$. Since Chilean wines are characterized by their strong ethanol content with $14 \%(v / v)$ as the average concentration, the use of the selected strains in sequential fermentation with $S$. cerevisiae might be an alternative for the production of reduced alcohol wines. Reduction of alcohol is of interest given that high concentrations of ethanol mask some wine attributes [70]. In addition, economical and health trends have influenced this market, and nowadays there a few vineyards that produce lower alcohol content wines.

Acetic acid production was similar for C. stellata and C. oleophila, with concentrations of 0.52 and $0.53 \mathrm{~g} / \mathrm{L}$, respectively (Table 7). The ability to produce acetic acid from sugar consumption has been reported before for Candida spp.; however, the values reported here are higher to those reported previously. Díaz et al., (2013) reported acetic acid concentrations 
ranging from 0.024 to $0.27 \mathrm{~g} / \mathrm{L}$. Although the acetic acid production might be considered a sign of microbial spoilage, $C$. stellata have not been reported as spoilage-causing agents. Moreover, the presence of the yeast that are able to persist towards the end of the alcoholic fermentations is associated with the enhancement of the sensory profile of the wine [103]. Compared to the control fermentations the sequential procedure resulted in higher acetic, malic, and succinic acid concentrations, which is consistent with what was previously reported in the literature $[38,41,46,104]$.

Table 7. Organic acids and glycerol observed in the C. stellata and C. oleophila, and sequential fermentations with S. cerevisiae.

\begin{tabular}{ccccc}
\hline \multirow{2}{*}{ Yeast } & Acetic Acid & Malic Acid & Succinic Acid & Glycerol \\
\cline { 2 - 5 } & \multicolumn{3}{c}{$(\mathrm{g} / \mathrm{L})$} \\
\hline C. stellata & $0.52 \pm 0.07^{\mathrm{a}}$ & $0.82 \pm 0.13^{\mathrm{a}}$ & $1.99 \pm 0.15^{\mathrm{a}}$ & $10.3 \pm 0.05^{\mathrm{a}}$ \\
C. oleophila & $0.53 \pm 0.11^{\mathrm{a}}$ & $0.65 \pm 0.15^{\mathrm{b}}$ & $2.31 \pm 0.01^{\mathrm{b}}$ & $18.1 \pm 0.05^{\mathrm{b}}$ \\
S. cerevisiae & $0.26 \pm 0.01^{\mathrm{c}}$ & $1.03 \pm 0.03^{\mathrm{d}}$ & $1.21 \pm 0.05^{\mathrm{d}}$ & $10.4 \pm 2.04^{\mathrm{a}}$ \\
\hline
\end{tabular}

Values represent mean \pm standard deviations for two independent sets and three replicates $(n=6)$ collected after 7 days of fermentation. Different lower-case letters within columns indicate significant differences $(p<0.05)$.

Succinic acid concentrations (Table 7) were detected in the range of 1.99 to $2.39 \mathrm{~g} / \mathrm{L}$. Although the concentrations fall above the usual range in wine $(0.5$ to $1.5 \mathrm{~g} / \mathrm{L})$, for some red wine varieties, concentrations higher that $3 \mathrm{~g} / \mathrm{L}$ have been reported without exerting a negative effect in the wine flavor $[41,70,105]$.

Malic acid production was strain specific with $0.08 \pm 0.13,0.06 \pm 0.05$, and $0.05 \pm 0.05 \mathrm{~g} / \mathrm{L}$ for C. stellata and C. oleophila, respectively, and all values were lower than the control fermentation (Table 7). These values are much lower than those reported for other nonSaccharomyces cultivated in limited aeration systems [70,104]. Some non-Saccharomyces yeasts have been reported as able to control the acidity of wines by metabolizing organic acids $[106,107]$. However, to our knowledge, no information for malic acid utilization or production for C. stellata and C. oleophila in wines has been reported before. However, the values reported here might indicate that the use of the yeast strains could result in less acidic wines, and even more, might help to reduce or eliminate the malolactic fermentation needed for the wines' stability. However, more studies are necessary to confirm this.

In the sequential fermentations $C$. oleophila produced the highest glycerol content (Table 7), approximately two times higher than the other two sequential fermentations. Glycerol is a non-volatile compound that is formed by sugar consumption during the yeast metabolism. The compound contributes to wine with sweetness and fullness by increasing the density and viscosity of the wine. The glycerol values achieved in the sequential fermentations are higher to those reported for other non-Saccharomyces yeasts in single, sequential, and co-inoculated fermentations [20]. The redirecting of ethanol production to other metabolites, including glycerol, has been reported as an approach to reduce the ethanol concentration. The selected yeast strains used in this study showed ethanol yields of 0.18 and 0.40 for C. oleophila and C. stellata, respectively (Table 5), and therefore, the increased glycerol concentration might be attributed to the yeast's ability to canalize sugar consumption into glycerol production. C. stellata fermentative potential has been studied not only in wines, but also in beer and vinegar production $[21,26,108]$. The fructophilic yeast metabolism is characterized by the production of glycerol instead of ethanol, and thus produces wines with reduced alcohol content [20]. On the other hand, to our knowledge, the use of $C$. oleophila for wine production has not been previously reported. Our results suggests that the yeasts have a potential for the production of reduced alcohol wines in sequential fermentations; however, more studies are necessary to determine the effect on aroma and sensory characteristics of the resulting wines. 


\section{Conclusions}

The seven grape cultivars (C. Sauvignon, Carignan, Chardonnay, Merlot, Pinot, S. Blanc, and Syrah) studied showed a great native yeast diversity in the fresh grape juice. Although S. cerevisiae became the dominant yeast after 7 days of fermentation, some non-Saccharomyces yeast were able to persist the ethanol conditions and were isolated from the fermented grape juices. In order of prevalence, species from Metschnikowia, Lachancea, Hanseniaspora, Candida, and Toulaspora were detected and isolated. The yeast-like fungus A. pullulans was also isolated, although its presence was encountered in low abundance. Three LAB species were also isolated. Two of them (Le. mesenteroides and L. delbrueckii) have been previously reported as malolactic positive, and might be responsible, along with the yeast population, for the low malic acid concentration achieved during the alcoholic fermentation, but more studies to confirm this ability, and its performance in co-culture or sequential fermentations with yeasts are needed.

The selected non-Saccharomyces yeasts showed a wide range of ethanol yields that were strain dependent. Among the isolated yeast, two Candida species were further studied to characterize the yeasts' ability to ferment in sequential fermentations with S. cerevisiae. The fermentations with the Candida species resulted in Carménère fermented grape juices with reduced ethanol concentrations $(10-12 \%(v / v))$, in comparison with the commercial S. cerevisiae strain, which presented ethanol content close to $14 \%(v / v)$. Regardless of the ethanol content, less acetic and malic concentrations were observed when compared to the control fermentations, which might positively impact the final wine acidity. High glycerol production in the fermentation with C. oleophila was observed, which might directly impact the wine mouthfeel. To our knowledge, this is the first time C. oleophina has been used for grape juice fermentations, and given its fermentation profile, the yeast might be a suitable candidate for wine production; however, the impact on wine flavor and the potential of producing desired (or not) aroma and flavor compounds need to be further studied.

Author Contributions: W.F. conceptualized the scientific approach, defined the experimental design, executed $60 \%$ of the experiments, conducted data analysis, manuscript drafting and revision, and funding acquisition. S.B. contributed with data interpretation, and reviewed/edited the manuscript. P.V. contributed with the experimental design conceptualization, reviewed/edited the manuscript, and funding acquisition. C.R. contributed with the experimental design conceptualization, reviewed/edited the manuscript, and funding acquisition. A.U. contributed to the study design, data analysis, manuscript drafting and revision, and funding acquisition. All authors have read and agreed to the published version of the manuscript.

Funding: This research was partially funded by the Fondef IDeA project CA12I10248 and the Fondef IDeA project ID19I10340.

Institutional Review Board Statement: Not applicable.

Informed Consent Statement: Not applicable.

Data Availability Statement: No public data was used.

Acknowledgments: The authors would like to thank María José Paredes and Camila Olea for their contribution on data gathering. We also give thanks to Viña Palo Alto (Concha y Toro, Chile) for providing grape berries and Viña Santa Emiliana (Chile) for providing the grape juice for the experiments.

Conflicts of Interest: The authors declare no conflict of interest.

\section{References}

1. Vilela, A. The Importance of Yeasts on Fermentation Quality and Human Health-Promoting Compounds. Fermentation 2019 , 5, 46. [CrossRef]

2. Jolly, N.P.; Varela, C.; Pretorius, I.S. Not Your Ordinary Yeast: Non-Saccharomyces Yeasts in Wine Production Uncovered. FEMS Yeast Res. 2014, 14, 215-237. [CrossRef]

3. Berbegal, C.; Spano, G.; Tristezza, M.; Grieco, F.; Capozzi, V. Microbial Resources and Innovation in the Wine Production Sector. S. Afr. J. Enol. Vitic. 2017, 38, 156-166. [CrossRef] 
4. Medina, K.; Boido, E.; Fariña, L.; Gioia, O.; Gomez, M.E.; Barquet, M.; Gaggero, C.; Dellacassa, E.; Carrau, F. Increased Flavour Diversity of Chardonnay Wines by Spontaneous Fermentation and Co-Fermentation with Han-Seniaspora Vineae. Food Chem. 2013, 141, 2513-2521. [CrossRef] [PubMed]

5. Barata, A.; Malfeito-Ferreira, M.; Loureiro, V. The Microbial Ecology of Wine Grape Berries. Int. J. Food Microbiol. 2012, 153, 243-259. [CrossRef]

6. Liu, Y.; Rousseaux, S.; Tourdot-Maréchal, R.; Sadoudi, M.; Gougeon, R.; Schmitt-Kopplin, P.; Alexandre, H. Wine Microbiome: A Dynamic World of Microbial Interactions. Crit. Rev. Food Sci. Nutr. 2015, 57, 856-873. [CrossRef] [PubMed]

7. Bokulich, N.A.; Ohta, M.; Richardson, P.M.; Mills, D.A. Monitoring Seasonal Changes in Winery-Resident Microbiota. PLoS ONE 2013, 8, e66437.

8. Zarraonaindia, I.; Owens, S.M.; Weisenhorn, P.; West, K.; Hampton-Marcell, J.; Lax, S.; Bokulich, N.A.; Mills, D.A.; Martin, G.; Taghavi, S.; et al. The Soil Microbiome Influences Grapevine-Associated Microbiota. mBio 2015, 6, e02527-14. [CrossRef]

9. Gilbert, J.A.; van der Lelie, D.; Zarraonaindia, I. Microbial Terroir for Wine Grapes. Proc. Natl. Acad. Sci. USA 2014, 111, 5-6. [CrossRef]

10. Combina, M.; Elía, A.; Mercado, L.; Catania, C.; Ganga, A.; Martinez, C. Dynamics of Indigenous Yeast Populations during Spontaneous Fermentation of Wines from Mendoza, Argentina. Int. J. Food Microbiol. 2005, 99, 237-243. [CrossRef]

11. Garofalo, C.; Russo, P.; Beneduce, L.; Massa, S.; Spano, G.; Capozzi, V. Non-Saccharomyces Biodiversity in Wine and the 'microbial Terroir': A Survey on Nero di Troia Wine from the Apulian Region, Italy. Ann. Microbiol. 2015, 66, 143-150. [CrossRef]

12. Knight, S.; Klaere, S.; Fedrizzi, B.; Goddard, M.R. Regional Microbial Signatures Positively Correlate with Differential Wine Phenotypes: Evidence for a Microbial Aspect to Terroir. Sci. Rep. 2015, 5, 14233. [CrossRef]

13. Vilela, A. Use of Nonconventional Yeasts for Modulating Wine Acidity. Fermentation 2019, 5, 27. [CrossRef]

14. Cordero-Bueso, G.; Esteve-Zarzoso, B.; Cabellos, J.M.; Gil-Díaz, M.; Arroyo, T. Biotechnological Potential of Non-Saccharomyces Yeasts Isolated During Spontaneous Fermentations of Malvar (Vitis Vinifera cv. L.). Eur. Food Res. Technol. 2012, 236, 193-207. [CrossRef]

15. Nikolaou, E.; Soufleros, E.H.; Bouloumpasi, E.; Tzanetakis, N. Selection of Indigenous Saccharomyces Cerevisiae Strains According to Their Oenological Characteristics and Vinification Results. Food Microbiol. 2006, 23, 205-211. [CrossRef] [PubMed]

16. Liu, P.-T.; Lu, L.; Duan, C.-Q.; Yan, G.-L. The Contribution of Indigenous Non-Saccharomyces Wine Yeast to Improved Aromatic Quality of Cabernet Sauvignon Wines by Spontaneous Fermentation. LWT Food Sci. Technol. 2016, 71, 356-363. [CrossRef]

17. Loira, I.; Morata, A.; Comuzzo, P.; Callejo, M.J.; González, C.; Calderón, F.; Suárez-Lepe, J.A. Use of Schizosac-Charomyces Pombe and Torulaspora Delbrueckii Strains in Mixed and Sequential Fermentations to Improve Red Wine Sensory Quality. Food Res. Int. 2015, 76, 325-333. [CrossRef]

18. González-Royo, E.; Pascual, O.; Kontoudakis, N.; Esteruelas, M.; Esteve-Zarzoso, B.; Mas, A.; Canals, J.M.; Zamora, F. Oenological Consequences of Sequential Inoculation with Non-Saccharomyces Yeasts (Torulaspora Del-Brueckii or Metschnikowia Pulcherrima) and Saccharomyces Cerevisiae in Base Wine for Sparkling Wine Production. Eur. Food Res. Technol. 2015, 240, 999-1012. [CrossRef]

19. Berbegal, C.; Khomenko, I.; Russo, P.; Spano, G.; Fragasso, M.; Biasioli, F.; Capozzi, V. PTR-ToF-MS for the Online Monitoring of Alcoholic Fermentation in Wine: Assessment of VOCs Variability Associated with Different Combinations of Saccharomyces/NonSaccharomyces as a Case-Study. Fermentation 2020, 6, 55. [CrossRef]

20. Fleet, G.H. Yeast Interactions and Wine Flavour. Int. J. Food Microbiol. 2003, 86, 11-22. [CrossRef]

21. Steensels, J.; Verstrepen, K.J. Taming Wild Yeast: Potential of Conventional and Nonconventional Yeasts in Industrial Fermentations. Annu. Rev. Microbiol. 2014, 68, 61-80. [CrossRef]

22. Tufariello, M.; Fragasso, M.; Pico, J.; Panighel, A.; Castellarin, S.D.; Flamini, R.; Grieco, F. Influence of Non-Saccharomyces on Wine Chemistry: A Focus on Aroma-Related Compounds. Molecules 2021, 26, 644. [CrossRef] [PubMed]

23. Padilla, B.; García-Fernández, D.; González, B.; Izidoro, I.; Esteve-Zarzoso, B.; Beltran, G.; Mas, A. Yeast Biodiversity from DOQ Priorat Uninoculated Fermentations. Front. Microbiol. 2016, 7, 930. [CrossRef]

24. Portillo M del, C.; Mas, A. Analysis of Microbial Diversity and Dynamics During Wine Fermentation of Grenache Grape Variety by High-Throughput Barcoding Sequencing. LWT Food Sci. Technol. 2016, 72, 317-321. [CrossRef]

25. Díaz, C.; Molina, A.M.; Nähring, J.; Fischer, R. Characterization and Dynamic Behavior of Wild Yeast during Spontaneous Wine Fermentation in Steel Tanks and Amphorae. BioMed Res. Int. 2013, 2013, 1-13. [CrossRef] [PubMed]

26. Clemente-Jimenez, J.M.; Mingorance-Cazorla, L.; Martínez-Rodríguez, S.; Las Heras-Vázquez, F.J.; Rodríguez-Vico, F. Molecular Characterization and Oenological Properties of Wine Yeasts Isolated During Spontaneous Fermentation of Six Varieties of Grape Must. Food Microbiol. 2004, 21, 149-155. [CrossRef]

27. Rementeria, A.; Rodriguez, J.A.; Cadaval, A.; Amenabar, R.; Muguruza, J.R.; Hernando, F.L.; Sevilla, M.J. Yeast Associated with Spontaneous Fermentations of White Wines from the "Txakoli de Bizkaia" Region (Basque Country, North Spain). Int. J. Food Microbiol. 2003, 86, 201-207. [CrossRef]

28. Li, E.; Liu, A.; Xue, B.; Liu, Y. Yeast Species Associated with Spontaneous Wine Fermentation of Cabernet Sauvignon from Ningxia, China. World J. Microbiol. Bioetchnol. 2011, 27, 2475-2482. [CrossRef]

29. Beckner Whitener, M.E.; Stanstrup, J.; Panzeri, V.; Carlin, S.; Divol, B.; Du Toit, M.; Vrhovsek, U. Untangling the Wine Metabolome by Combining Untargeted SPME-GCxGC-TOF-MS and Sensory Analysis to Profile Sauvignon Blanc Cofermented with Seven Different Yeasts. Metabolomics 2016, 12, 1-25. [CrossRef] 
30. Ivit, N.N.; Longo, R.; Kemp, B. The Effect of Non-Saccharomyces and Saccharomyces Non-Cerevisiae Yeasts on Ethanol and Glycerol Levels in Wine. Fermentation 2020, 6, 77. [CrossRef]

31. Sun, Y.; Liu, Y. Investigating of Yeast Species in Wine Fermentation Using Terminal Restriction Fragment Length Polymorphism Method. Food Microbiol. 2014, 38, 201-207. [CrossRef]

32. Wang, C.; Mas, A.; Esteve-Zarzoso, B. Interaction between Hanseniaspora Uvarum and Saccharomyces Cerevisiae during Alcoholic Fermentation. Int. J. Food Microbiol. 2015, 206, 67-74. [CrossRef]

33. Grangeteau, C.; Gerhards, D.; Rousseaux, S.; von Wallbrunn, C.; Alexandre, H.; Guilloux-Benatier, M. Diversity of Yeast Strains of the Genus Hanseniaspora in the Winery Environment: What is Their Involvement in Grape Must Fermentation? Food Microbiol. 2015, 50, 70-77. [CrossRef] [PubMed]

34. Wang, C.; Esteve-Zarzoso, B.; Mas, A. Monitoring of Saccharomyces Cerevisiae, Hanseniaspora Uvarum, and Starmerella Bacillaris (Synonym Candida Zemplinina) Populations during Alcoholic Fermentation by Fluorescence In Situ Hybridization. Int. J. Food Microbiol. 2014, 191, 1-9. [CrossRef] [PubMed]

35. Canonico, L.; Agarbati, A.; Comitini, F.; Ciani, M. Torulaspora Delbrueckii in the Brewing Process: A New Approach to Enhance Bioflavour and to Reduce Ethanol Content. Food Microbiol. 2016, 56, 45-51. [CrossRef] [PubMed]

36. Azzolini, M.; Tosi, E.; Lorenzini, M.; Finato, F.; Zapparoli, G. Contribution to the Aroma of White Wines by Controlled Torulaspora Delbrueckii Cultures in Association with Saccharomyces Cerevisiae. World J. Microbiol. Biotechnol. 2014, 31, 277-293. [CrossRef]

37. Contreras, A.; Curtin, C.; Varela, C. Yeast Population Dynamics Reveal a Potential 'Collaboration' between Metschnikowia Pulcherrima and Saccharomyces Uvarum for the Production of Reduced Alcohol Wines during Shiraz Fermentation. Appl. Microbiol. Biotechnol. 2014, 99, 1885-1895. [CrossRef] [PubMed]

38. Parapouli, M.; Hatziloukas, E.; Drainas, C.; Perisynakis, A. The Effect of Debina Grapevine Indigenous Yeast Strains of Metschnikowia and Saccharomyces on Wine Flavour. J. Ind. Microbiol. Biotechnol. 2010, 37, 85-93. [CrossRef]

39. Morales, P.; Rojas, V.; Quirós, M.; Gonzalez, R. The Impact of Oxygen on the Final Alcohol Content of Wine Fermented by a Mixed Starter Culture. Appl. Microbiol. Biotechnol. 2015, 99, 3993-4003. [CrossRef]

40. Domizio, P.; Liu, Y.; Bisson, L.F.; Barile, D. Use of Non-Saccharomyces Wine Yeasts as Novel Sources of Mannoproteins in Wine. Food Microbiol. 2014, 43, 5-15. [CrossRef]

41. Gobbi, M.; Comitini, F.; Domizio, P.; Romani, C.; Lencioni, L.; Mannazzu, I.; Ciani, M. Lachancea Thermotolerans and Saccharomyces Cerevisiae in Simultaneous and Sequential Co-Fermentation: A Strategy to Enhance Acidity and Improve the Overall Quality of Wine. Food Microbiol. 2013, 33, 271-281. [CrossRef]

42. Benito, Á.; Calderón, F.; Palomero, F.; Benito, S. Combine Use of Selected Schizosaccharomyces Pombe and Lachancea Thermotolerans Yeast Strains as an Alternative to the Traditional Malolactic Fermentation in Red Wine Production. Molecules 2015, 20, 9510-9523. [CrossRef]

43. Hranilovic, A.; Gambetta, J.M.; Schmidtke, L.; Boss, P.K.; Grbin, P.R.; Masneuf-Pomarede, I.; Bely, M.; Albertin, W.; Jiranek, V. Oenological Traits of Lachancea Thermotolerans Show Signs of Domestication and Allopatric Differentiation. Sci. Rep. 2018, 8, 1-13. [CrossRef]

44. Comitini, F.; Gobbi, M.; Domizio, P.; Romani, C.; Lencioni, L.; Mannazzu, I.; Ciani, M. Selected Non-Saccharomyces Wine Yeasts in Controlled Multistarter Fermentations with Saccharomyces Cerevisiae. Food Microbiol. 2011, 28, 873-882. [CrossRef]

45. Wang, C.; Mas, A.; Esteve-Zarzoso, B. The Interaction between Saccharomyces Cerevisiae and Non-Saccharomyces Yeast during Alcoholic Fermentation Is Species and Strain Specific. Front. Microbiol. 2016, 7, 502. [CrossRef]

46. Canonico, L.; Comitini, F.; Oro, L.; Ciani, M. Sequential Fermentation with Selected Immobilized Non-Saccharomyces Yeast for Reduction of Ethanol Content in Wine. Front. Microbiol. 2016, 7, 278. [CrossRef]

47. Varela, C.; Sengler, F.; Solomon, M.; Curtin, C. Volatile Flavour Profile of Reduced Alcohol Wines Fermented with the NonConventional Yeast Species Metschnikowia Pulcherrima and Saccharomyces Uvarum. Food Chem. 2016, 209, 57-64. [CrossRef]

48. Berbegal, C.; Borruso, L.; Fragasso, M.; Tufariello, M.; Russo, P.; Brusetti, L.; Spano, G.; Capozzi, V. A Meta-Genomic-Based Approach for the Characterization of Bacterial Diversity Associated with Spontaneous Malolactic Fermentations in Wine. Int. J. Mol. Sci. 2019, 20, 3980. [CrossRef]

49. Ortiz, M.J.; Barrajón, N.; Baffi, M.A.; Arévalo-Villena, M.; Briones, A. Spontaneous Must Fermentation: Identification and Biotechnological Properties of Wine Yeasts. LWT Food Sci. Technol. 2013, 50, 371-377. [CrossRef]

50. Brysch-Herzberg, M.; Seidel, M. Yeast Diversity on Grapes in Two German Wine Growing Regions. Int. J. Food Microbiol. 2015, 214, 137-144. [CrossRef]

51. Jara, C.; Laurie, V.F.; Mas, A.; Romero, J. Microbial Terroir in Chilean Valleys: Diversity of Non-Conventional Yeast. Front. Microbiol. 2016, 7, 663. [CrossRef]

52. McFeeters, R.F.; Barish, A.O. Sulfite Analysis of Fruits and Vegetables by High-Performance Liquid Chromatography (HPLC) with Ultraviolet Spectrophotometric Detection. J. Agric. Food Chem. 2003, 51, 1513-1517. [CrossRef]

53. Iland, P.; Grodin, P.; Grinbergs, M.; Schmidtke, L.; Soden, A. Microbiologycal Analysis of Grapes and Wine: Techniques and Concepts; Wine Promotions Pty Ltd.: Sydney, Australia, 2001.

54. Franco, W.; Pérez-Díaz, I.M.; Johanningsmeier, S.D.; McFeeters, R.F. Characteristics of Spoilage-Associated Secondary Cucumber Fermentation. Appl. Environ. Microbiol. 2012, 78, 1273-1284. [CrossRef] [PubMed] 
55. Barrangou, R.; Yoon, S.-S.; Breidt, F.; Fleming, H.P.; Klaenhammer, T.R. Identification and Characterization of Leuconostoc Fallax Strains Isolated from an Industrial Sauerkraut Fermentation Identification and Characterization of Leuconostoc Fallax Strains Isolated from an Industrial Sauerkraut Fermentation. Appl. Environ. Microbiol. 2002, 68, 2877-2884. [CrossRef]

56. Wilson, K.H.; Blitchington, R.B.; Greene, R.C. Amplification of Bacterial 16S Ribosomal DNA with Polymerase Chain Reaction. J. Clin. Microbiol. 1990, 28, 1942-1946. [CrossRef] [PubMed]

57. Kurtzman, C.P.; Robnett, C.J. Identification of clinically important ascomycetous yeasts based on nucleotide divergence in the $5^{\prime}$ end of the large-subunit (26S) ribosomal DNA gene. J. Clin. Microbiol. 1997, 35, 1216. [CrossRef]

58. Altschul, S.F.; Gish, W.; Miller, W.; Myers, E.W.; Lipman, D.J. Basic Local Alignment Search Tool. J. Mol. Biol. 1990, 215, 403-410. [CrossRef]

59. Benson, D.A.; Cavanaugh, M.; Clark, K.; Mizrachi, I.K.; Lipman, D.J.; Ostell, J.; Sayers, E.W. GenBank. Nucleic Acids Res. 2012, 41, D36-D42. [CrossRef]

60. Franco, W.; Pérez-Díaz, I.M.; Connelly, L.; Diaz, J. Isolation of Exopolysaccharide-Producing Yeast and Lactic Acid Bacteria from Quinoa (Chenopodium Quinoa) Sourdough Fermentation. Foods 2020, 9, 337. [CrossRef]

61. Pan, Y.; Breidt, F. Enumeration of Viable Listeria monocytogenes Cells by Real-Time PCR with Propidium Monoazide and Ethidium Monoazide in the Presence of Dead Cells. Appl. Environ. Microbiol. 2007, 73, 8028-8031. [CrossRef]

62. Sinclair, L.; Osman, O.A.; Bertilsson, S.; Eiler, A. Microbial Community Composition and Diversity via 16S rRNA Gene Amplicons: Evaluating the Illumina Platform. PLoS ONE 2015, 10, e0116955. [CrossRef]

63. Bolger, A.M.; Lohse, M.; Usadel, B. Trimmomatic: A flexible Trimmer for Illumina Sequence Data. Bioinformatics 2014, 30, 2114-2120. [CrossRef]

64. Caporaso, J.G.; Kuczynski, J.; Stombaugh, J.; Bittinger, K.; Bushman, F.D.; Costello, E.K.; Fierer, N.; Peña, A.G.; Goodrich, J.K.; Gordon, J.I.; et al. QIIME Allows Analysis of High-Throughput Community Sequencing Data. Nat. Methods 2010, 7, $335-336$. [CrossRef]

65. Aronesty, E. Eautils: Command-Line Tools for Processing Biological Sequencing Data; Expression Analysis: Durham, NC, USA, 2011.

66. Rognes, T.; Flouri, T.; Nichols, B.; Quince, C.; Mahé, F. Vsearch: A Versatile Open Source Tool for Metagenomics. PeerJ 2016, 4, e2584. [CrossRef] [PubMed]

67. Quast, C.; Pruesse, E.; Yilmaz, P.; Gerken, J.; Schweer, T.; Yarza, P.; Peplies, J.; Glöckner, F.O. The SILVA Ribosomal RNA Gene Database Project: Improved Data Processing and Web-Based Tools. Nucl. Acids 2013, 41, D590-D596. [CrossRef]

68. Yilmaz, P.; Parfrey, L.W.; Yarza, P.; Gerken, J.; Pruesse, E.; Quast, C.; Schweer, T.; Peplies, J.; Ludwig, W.; Glöckner, F.O. The SILVA and "All-Species Living Tree Project (LTP)" Taxonomic Frameworks. Nucl. Acids 2014, 42, D643-D648. [CrossRef] [PubMed]

69. Caporaso, J.G.; Bittinger, K.; Bushman, F.D.; DeSantis, T.Z.; Andersen, G.L.; Knight, R. PyNAST: A Fexible Tool for Aligning Sequences to a Template Alignment. Bioinformatics 2010, 26, 266-267. [CrossRef]

70. Contreras, A.; Hidalgo, C.; Schmidt, S.; Henschke, P.; Curtin, C.; Varela, C. The Application of Non-Saccharomyces Yeast in Fermentations with Limited Aeration as a Strategy for the Production of Wine with Reduced Alcohol Content. Int. J. Food Microbiol. 2015, 205, 7-15. [CrossRef] [PubMed]

71. Wine of Chile. Carmenère. Available online: https://www.winesofchile.org/chile-vitivinicola/diversidad-vitivinicola/ carmenere/ (accessed on 2 January 2021).

72. Comitini, F.; Ciani, M. Influence of Fungicide Treatments on the Occurrence of Yeast Flora Associated with Wine Grapes. Ann. Microbiol. 2008, 58, 489-493. [CrossRef]

73. Martins, G.; Vallance, J.; Mercier, A.; Albertin, W.; Stamatopoulos, P.; Rey, P.; Lonvaud, A.; Masneuf-Pomarede, I. Influence of the Farming System on the Epiphytic Yeasts and Yeast-Like Fungi Colonizing Grape Berries during the Ripening Process. Int. J. Food Microbiol. 2014, 177, 21-28. [CrossRef]

74. Renouf, V.; Claisse, O.; Lonvaud-Funel, A. Understanding the Microbial Ecosystem on the Grape Berry Surface through Numeration and Identification of Yeast and Bacteria. Aust. J. Grape Wine Res. 2005, 11, 316-327. [CrossRef]

75. Ministerio del Medio Ambiente. Región del MAULE Normales Climatológicas. Available online: http://basedigitaldelclima. mma.gob.cl/pdf_estudio_dos/9Maule.pdf (accessed on 17 February 2021).

76. Alexandre, H. Wine Yeast Terroir: Separating the Wheat from the Chaff-for an Open Debate. Microorganisms 2020, 8, 787. [CrossRef]

77. Gamboa, G.G.; Moreno-Simunovic, Y. Location Effects on Ripening and Grape Phenolic Composition of Eight 'Carignan' Vineyards from Maule Valley (Chile). Chil. J. Agric. Res. 2018, 78, 139-149. [CrossRef]

78. Li, S.-S.; Cheng, C.; Li, Z.; Chen, J.; Yan, B.; Han, B.-Z.; Reeves, M. Yeast Species Associated with Wine Grapes in China. Int. J. Food Microbiol. 2010, 138, 85-90. [CrossRef]

79. Catrileo, D.; Acuña-Fontecilla, A.; Godoy, L. Adaptive Laboratory Evolution of Native Torulaspora Delbrueckii YCPUC10 with Enhanced Ethanol Resistance and Evaluation in Co-Inoculated Fermentation. Front. Microbiol. 2020, 11. [CrossRef] [PubMed]

80. Ciani, M.; Maccarelli, F. Oenological Properties of Non-Saccharomyces Yeasts Associated with Wine-Making. World J. Microbiol. Biotechnol. 1997, 14, 199-203. [CrossRef]

81. Binati, R.L.; Junior, W.J.L.; Luzzini, G.; Slaghenaufi, D.; Ugliano, M.; Torriani, S. Contribution of Non-Saccharomyces Yeasts to Wine Volatile and Sensory Diversity: A Study on Lachancea Thermotolerans, Metschnikowia spp. and Starmerella Bacillaris Strains Isolated in Italy. Int. J. Food Microbiol. 2020, 318, 108470. [CrossRef] 
82. Hranilovic, A.; Gambetta, J.M.; Jeffery, D.W.; Grbin, P.R.; Jiranek, V. Lower-Alcohol Wines Produced by Metschnikowia Pulcherrima and Saccharomyces Cerevisiae Co-Fermentations: The Effect of Sequential Inoculation Timing. Int. J. Food Microbiol. 2020, 329, 108651. [CrossRef]

83. Belda, I.; Ruiz, J.; Beisert, B.; Navascués, E.; Marquina, D.; Calderón, F.; Rauhut, D.; Benito, S.; Santos, A. Influence of Torulaspora Delbrueckii in Varietal Thiol (3-SH and 4-MSP) Release in Wine Sequential Fermentations. Int. J. Food Microbiol. 2017, $257,183-191$. [CrossRef]

84. Belda, I.; Navascués, E.; Marquina, D.; Santos, A.; Calderon, F.; Benito, S. Dynamic Analysis of Physiological Properties of Torulaspora Delbrueckii in Wine Fermentations and Its Incidence on Wine Quality. Appl. Microbiol. Biotechnol. 2015, 99, 1911-1922. [CrossRef] [PubMed]

85. Onetto, C.A.; Borneman, A.R.; Schmidt, S.A. Investigating the Effects of Aureobasidium Pullulans on Grape Juice Composition and Fermentation. Food Microbiol. 2020, 90, 103451. [CrossRef]

86. Pinto, C.; Pinho, D.; Sousa, S.; Pinheiro, M.; Egas, C.; Gomes, A.C. Unravelling the Diversity of Grapevine Microbiome. PLoS ONE 2014, 9, e85622. [CrossRef]

87. Vaudano, E.; Quinterno, G.; Costantini, A.; Pulcini, L.; Pessione, E.; Garcia-Moruno, E. Yeast Distribution in Grignolino Grapes Growing in a New Vineyard in Piedmont and the Technological Characterization of Indigenous Saccharomyces spp. Strains. Int. J. Food Microbiol. 2019, 289, 154-161. [CrossRef]

88. Cravero, M.C. Organic and Biodynamic Wines Quality and Characteristics: A review. Food Chem. 2019, 295, 334-340. [CrossRef] [PubMed]

89. Fleet, G.H. Wine. In Food Microbiology Fundamentals and Fronteirs; Doyle, M.P., Beuchat, L.R., Monteville, J.T., Eds.; ASM Press: Washington, DC, USA, 2001; pp. 747-772.

90. Kačániová, M.; Kunová, S.; Sabo, J.; Ivanišová, E.; Žiarovská, J.; Felšöciová, S.; Fatrcová-Šramková, K.; Terentjeva, M. Isolation and Identification of Lactic Acid Bacteria in Wine Production by Maldi-Tof MS Biotyper. Acta Hortic. Regiotect. 2020, 23, 21-24. [CrossRef]

91. Pittet, V.; Morrow, K.; Ziola, B. Ethanol Tolerance of Lactic Acid Bacteria, Including Relevance of the Exopolysaccharide GeneGtf. J. Am. Soc. Brew. Chem. 2011, 69, 57-61. [CrossRef]

92. García-Ruiz, A.; Moreno-Arribas, M.; Martín-Álvarez, P.J.; Bartolomé, B. Comparative Study of the Inhibitory Effects of Wine Polyphenols on the Growth of Enological Lactic Acid Bacteria. Int. J. Food Microbiol. 2011, 145, 426-431. [CrossRef] [PubMed]

93. López-Seijas, J.; García-Fraga, B.; Da Silva, A.F.; Zas-García, X.; Lois, L.C.; Gago-Martínez, A.; Leão-Martins, J.M.; Sieiro, C. Evaluation of Malolactic Bacteria Associated with Wines from Albariño Variety as Potential Starters: Screening for Quality and Safety. Foods 2020, 9, 99. [CrossRef] [PubMed]

94. Mendoza, L.M.; de Nadra, M.C.M.; Farías, M.E. Antagonistic Interaction between Yeasts and Lactic Acid Bacteria of Oenological Relevance: Partial Characterization of Inhibitory Compounds Produced by Yeasts. Food Res. Int. 2010, 43, 1990-1998. [CrossRef]

95. Capozzi, V.; Tufariello, M.; De Simone, N.; Fragasso, M.; Grieco, F. Biodiversity of Oenological Lactic Acid Bacteria: Species- and Strain-Dependent Plus/Minus Effects on Wine Quality and Safety. Fermentation 2021, 7, 24. [CrossRef]

96. Álvarez-Fernández, M.A.; Fernández-Cruz, E.; Garcia-Parrilla, M.C.; Troncoso, A.M.; Mattivi, F.; Vrhovsek, U.; Arapitsas, P. Saccharomyces Cerevisiae and Torulaspora Delbrueckii Intra- and Extra-Cellular Aromatic Amino Acids Metabolism. J. Agric. Food Chem. 2019, 67, 7942-7953. [CrossRef]

97. García, M.; Esteve-Zarzoso, B.; Cabellos, J.M.; Arroyo, T. Advances in the Study of Candida Stellata. Fermentation 2018, 4, 74. [CrossRef]

98. Ciani, M.; Ferraro, L. Combined Use of Immobilized Candida Stellata Cells and Saccharomyces Cerevisiae to Improve the Quality of Wines. J. Appl. Microbiol. 1998, 85, 247-254. [CrossRef]

99. Beltran, G.; Torija, M.J.; Novo, M.; Ferrer, N.; Poblet, M.; Guillamón, J.M.; Rozès, N.; Mas, A. Analysis of Yeast Populations during Alcoholic Fermentation: A Six Year Follow-Up Study. Syst. Appl. Microbiol. 2002, 25, 287-293. [CrossRef]

100. Hong, Y.-A.; Park, H.-D. Role of Non-Saccharomyces Yeasts in Korean Wines Produced from Campbell Early Grapes: Potential Use of Hanseniaspora Uvarum as a Starter Culture. Food Microbiol. 2013, 34, 207-214. [CrossRef]

101. Benito, S. The impact Of Torulaspora Delbrueckii Yeast in Winemaking. Appl. Microbiol. Biotechnol. 2018, 102, 3081-3094. [CrossRef]

102. Domizio, P.; Lencioni, L.; Ciani, M.; Di Blasi, S.; Pontremolesi, C.; Sabatelli, M. Spontaneous and Inoculated Yeast Populations Dynamics and Their Effect on Organoleptic Characters of Vinsanto Wine under Different Process Conditions. Int. J. Food Microbiol. 2007, 115, 281-289. [CrossRef]

103. UC DAVIS. Wine Microbiology; The University of California: Davis, CA, USA, 2011. Available online: https://wineserver.ucdavis. edu/industry-info/enology/wine-microbiology (accessed on 2 July 2020).

104. Contreras, A.; Hidalgo, C.; Henschke, P.A.; Chambers, P.J.; Curtin, C.; Varela, C. Evaluation of Non-Saccharomyces Yeasts for the Reduction of Alcohol Content in Wine. Appl. Environ. Microbiol. 2014, 80, 1670-1678. [CrossRef]

105. Ciani, M.; Morales, P.; Comitini, F.; Tronchoni, J.; Canonico, L.; Curiel, J.A.; Oro, L.; Rodrigues, A.J.; Gonzalez, R. NonConventional Yeast Species for Lowering Ethanol Content of Wines. Front. Microbiol. 2016, 7, 642. [CrossRef]

106. Englezos, V.; Torchio, F.; Cravero, F.; Marengo, F.; Giacosa, S.; Gerbi, V.; Rantsiou, K.; Rolle, L.; Cocolin, L. Aroma prfile and comosition of Barbera by of Starmerella bacillaris (syonym Candida zemplinina) and Saccharomyces ceevisiae. LWT 2016, 73, 567-575. [CrossRef] 
107. Englezos, V.; Rantsiou, K.; Torchio, F.; Rolle, L.; Gerbi, V.; Cocolin, L. Exploitation of the Non-Saccharomyces Yeast Starmerella Bacillaris (Synonym Candida zemplinina) in Wine Fermentation: Physiological and Molecular Characterizations. Int. J. Food Microbiol. 2015, 199, 33-40. [CrossRef] [PubMed]

108. Ciani, M.; Ferraro, L.; Fatichenti, F. Influence of Glycerol Production on the Aerobic and Anaerobic Growth of the Wine Yeast Candida Stellata. Enzym. Microb. Technol. 2000, 27, 698-703. [CrossRef] 